\title{
ÓXIDOS DE Fe E TI DO DEPÓSITO DE COBRE DE SURUBIM, VALE DO CURAÇÁ, BA
}

\author{
ROSA MARIA DA SILVEIRA BELLO*, JOSÉ VICENTE VALARELLI**, \\ JOHILDO S. FIGUEIREDO BARBOSA*** e RAINER SCHULTZ-GÜTTLER**
}

\begin{abstract}
Fe AND Ti OXIDES FROM THE SURUBIM COPPER DEPOSIT, CURAÇÁ VALLEY, BAHIA. The Surubim copper deposit belongs to the Curaça River Valley Copper Province, Bahia, characterized by high-grade precambrian terranes. The mineralization is present as disseminated copper and iron sulfides in granulitic bodies with mafic-ultramafic compositions, enclosed in gneisses of several kinds. Lenses of calc-silicate rocks and iron-formations, besides garnet-rich or graphitic horizons, occur associated with these rocks. The iron-titanium oxides, frequent in mineralized and country rocks, are associated with sulfides and certain silicates. Mineralogical, textural and paragenetic aspects of these minerals, and the application of geothermometry/oxygen barometry methos in coexisting magnetite-ilmenite reflect the complexity of the post-granulitic subsolidus cooling history. The data suggest that these reequilibrations ceased at quite low temperatures, and reached oxygen fugacities close to the HM buffer curve. The T and $\mathrm{fO}_{2}$ conditions in the peak of the granulitic metamorphism were obtained from geothermobarometric methods, with the original oxide composition estimated. Depending on the method used to recalculate the original composition of the ilmenites, the following $\mathrm{T}$ and $\mathrm{fO}_{2}$ ranges were determined: $\mathrm{T}=617$ to $780^{\circ} \mathrm{C} / \log f_{\mathrm{O}_{2}}=-17,68$ to $-13,37$ and $\mathrm{T}=675$ to $780^{\circ} \mathrm{C} / \log f \mathrm{O}_{2}=-15,24$ to $-13,37$. In a $\mathrm{T} \times \log f_{\mathrm{O}_{2}}$ diagram these values are located close to or slightly above the $\mathrm{QMF}$ buffer curve. These results define the peak of the granulitic metamorphism, with average temperatures similar to those obtained by other geothermometric methods.
\end{abstract}

INTRODUÇĀO O depósito de cobre de Surubim, com reservas de 14 milhöes de toneladas a $0,8 \% \mathrm{Cu}$, faz parte da província cuprífera do Vale do Rio Curaçá, localizada na parte norte-nordeste do Estado da Bahia. Esta província e caracterizada por terrenos pré-cambrianos de alto grau metamórfico, sendo constituída por gnaisses e granulitos, com núcleos migmatíticos, mostrando uma complexidade estrutural e litológica bastante acentuada.

Aspectos estruturais, litológicos, estratigráficos e petrológicos dessa província, bem como a gênese dos depósitos de cobre, têm sido objeto de vários trabalhos: Figueiredo (1976, 1981), Lindenmayer (1981), Sá et al. (1982), Hasui et al. (1982), Franke et al. (1982), Sá \& Reinhardt (1984), Silva (1985) e Bello (1986).

O depósito de Surubim se caracteriza pela presença de sulfetos de cobre e ferro disseminados, localmente concentrados, em granulitos de composição máfica-ultramáfica (granulitos piroxeníticos, noríticos e biotititos). Mineralização de mais baixo teor ocorre também em granulitos gabronoríticos e gábricos. Os corpos mineralizados se encaixam em gnaisses de naturezas diversas (gnaisses quartzo-feldspáticos, gnaisses quartzo-dioríticos, biotita-ortopiroxênio gnaisses e gnaisses de composiçōes gabronoríticas e quartzo gabronoríticas), aos quais se associam rochas cálcio-silicatadas e formaçōes ferríferas (Bello 1986). Deve ainda ser mencionado que granada e grafita ocorrem de modo aleatório em todos os tipos de rochas observados em Surubim (Bello op. cit.).

Indicaçōes de campo, estudos mineralógicos, petrográficos, petroquímicos e o quimismo mineral de várias fases presentes em Surubim sugerem um ambiente vulcano-sedimentar original (Figueiredo 1976, e 1981, Bello 1986). Atualmente, são observadas paragêneses indicativas de metamorfismo de alto grau, fácies granulito, ocorrendo também feiçōes que evidenciam a existência de episódios retrometamórficos, com desenvolvimento de associaçōes mineralógicas representativas de fácies xistos verdes e, localmente, de mais baixo grau. Aspectos do metamorfismo, especificamente para a regiāo de Surubim, são discutidos em Franke et al. (1982) e Bello (op. cit.).

A mineralização é constituída essencialmente por calcopirita, bornita e idaíta. Esses minerais podem estar associados a 6xidos de ferro e titânio, pirrotita, pentlandita e, ocasionalmente, a pirita e arsenopirita. Ocorrem ainda calcocita, digenita, covelita e anilita-djurleíta, provenientes de transformaçōes a partir de calcopirita, bornita e idaíta, além de carbonatos de cobre supérgenos. Também é comum a presença de grafita, além de teluretos de $\mathrm{Ni}, \mathrm{Cu}$ e $\mathrm{Pb}$, estes englobados em calcopirita e bornita (Bello 1986, Bello \& Valarelli 1986).

Magnetitas e ilmenitas, fases constantes nas rochas mineralizadas e encaixantes de Surubim, ocorrem em proporçōes variáveis nos diferentes tipos petrográficos. A associação das soluçōes sólidas magnetita-ulvoespinélio (MT-USP)ss e ilmenita-hematita (ILM-HEM)ss pode fornecer informações úteis sobre as condições de metamorfismo atuantes na região e sobre os reequilíbrios subsólidos posteriores, uma vez que as composiçōes dessas fases coexistentes sāo funçōes da temperatura e da fugacidade de oxigênio (Buddington \& Lindsley 1964, Powell \& Powell 1977).

Este trabalho teve por objetivo a determinação das condiçōes de $\mathrm{T}$ e $f \mathrm{O}_{2}$ prevalescentes durante o pico do metamorfismo e a caracterização dos reequilíbrios subsólidos posteriores, com base nos estudos dos óxidos de ferro e titânio e na aplicação dos métodos de geotermometria-barometria de oxigênio. Para sua realizaçāo, foram examinadas cerca de 50 seçōes polidas e delgada-polidas de amostras de furos de sonda, galerias e trincheiras de Surubim, utilizando-se técnicas de luz transmitida e refletida, tendo sido salientados os aspectos mineralógicos, texturais e paragenéticos. Analises químicas desses minerais foram realizadas na Faculté Pierre et Marie Curie (Jussieu), em Paris, por um dos autores (Barbosa, J.S.F.), pelo

* Bolsista recém-doutor. Departamento de Metalogênesese e Geoquímica do Instituto de Geociências da Universidade Estadual de Campinas (UNICAMP). Departamento de Mineralogia e Petrologia do Instituto de Geociências da Universidade de São Paulo (USP). Caixa Postal 20899, CEP 01498, São Paulo, SP, Brasil

** Departamento de Mineralogia e Petrologia do Instituto de Geociências, Universidade de São Paulo. Caixa Postal 20899, CEP 01498, São Paulo, SP, Brasil

*** Instituto de Geociências, Universidade Federal da Bahia. Rua Caetano Moura, 123, Federação, CEP 40000, Salvador, BA, Brasil 
método de Dispersão de Energia.

\section{ÓXIDOS DE FERRO E TITÂNIO Modo de ocorrên-} cia Os principais óxidos encontrados nas amostras de Surubim foram magnetita e ilmenita associados a espinélios ricos em ferro, de composiçōes próximas à hercinita. Secundariamente, ocorrem hematita, leucoxênio, goethita e outros oxi-hidróxidos de ferro formados a partir de magnetita e ilmenita. Rutilo foi observado, ocasionalmente, como finas inclusōes em ilmenita e como agulhas englobadas por biotita semi-alterada.

Os óxidos se apresentam em proporções variáveis nos diferentes tipos de rocha de Surubim. As maiores porcentagens de óxidos (principalmente magnetita) foram observadas em biotititos e certos granulitos piroxeníticos, que podem conter até $50 \%$ desses minerais. Nessas rochas, a magnetita ocorre sob a forma de cristais alongados e orientados, associados a sulfetos, com granulaçōes variando entre 0,5 e $1,7 \mathrm{~mm}$ (dimensão do maior eixo), dispostos em bandas que se alternam com faixas de biotitas orientadas ou de composiçōes piroxeníticas (Bello 1986).

Os granulitos noríticos e outros granulitos piroxeníticos, por outro lado, contêm menores porcentagens de óxidos (de $1 \%$ a $5 \%$ ), normalmente presentes como cristais intersticiais disseminados, sendo comum a textura granoblástica, na qual as magnetitas se encontram em equilibrio com piroxênios, espinélios e, localmente, ilmenita (Pr. 1, foto A).

Em granulitos noríticos parcialmente biotitizados, os óxidos ocorrem em proporçōes intermediárias, associados, muitas vezes, a sulfetos de cobre e ferro.

Em amostras de formaçöes ferriferas, foram observados apenas cristais de magnetita (de 1,7 a 2,0 mm), que, de modo semelhante a certos biotititos e granulitos piroxeníticos, encontram-se dispostos em bandas orientadas. Essas bandas se alternam com outras nas quais predomina o quartzo, podendo, no entanto, conter outros minerais, como plagioclásio, clinopiroxênio, anfibólio e, em certos casos, granada e carbonatos finos (Bello 1986). Neste caso, a magnetita é constituída apenas por $\mathrm{Fe}_{3} \mathrm{O}_{4}$ e contém, freqüentemente, lamelas de hematita bem desenvolvidas, feiçōes essas que são mais raras, mas nem sempre ausentes, nos outros tipos petrográficos (Bello op. cit.).

Tais observações permitem sugerir a existência de um acentuado controle litológico para os óxidos de ferro e titânio de Surubim, que deve refletir as condiçōes mais próximas das originais, uma vez que esses minerais apresentam menores mobilidades que os sulfetos.

Feiçōes que denotam fenômenos de abaixamento de temperatura e mudanças nas condiçōes de oxidaçāo, tais como intercrescimentos de ilmenita e espinélio em magnetita, sâo bastante freqüentes. Além disso, as magnetitas e ilmenitas podem apresentar contornos irregulares ou arredondados, sugerindo reaçōes de borda, após o metamorfismo granulítico. Também foram observados aspectos texturais indicativos da presença de mais de uma geraçāo de óxidos (Bello 1986).

Feições microscópicas - Mineralogia e texturas Magnetita: Ocorre, na maioria das vezes, como cristais anédricos a subédricos e, ocasionalmente, euédricos. Sua granulaçāo varia entre $0,01 \mathrm{~mm}$ e $2,00 \mathrm{~mm}$, sendo maiores os cristais de magnetita dispostos em bandas nos biotititos, em certos granulitos piroxeníticos e nas amostras de formaçōes ferríferas. Pode estar associada à ilmenita, a espinélios, sulfetos de cobre e ferro e a certos silicatos.

Os cristais de magnetita freqüentemente mostram variedades de microintercrescimentos de espinélio e ilmenita, que, segundo Buddington \& Lindsley (1964) e Haggerty (1976a e b), seriam indicativos de variações nas condiçốes de oxidação e nas velocidades de resfriamento, durante as fases de reequilibrios subsólidos posteriores ao pico do metamorfismo.
Os intercrescimentos de ilmenita se apresentam sob a forma de grânulos internos e externos, ou como lamelas de dimensōes variáveis, desenvolvidas paralelamente aos planos (111) da magnetita hospedeira (Pr. 1, fotos B, C, e D). Também são comuns lamelas de espinélio orientadas segundo planos (100) da magnetita, bem como intercrescimentos irregulares desse mineral (Pr. 1, fotos B, C e D).

Por meio de dados experimentais, Buddington \& Lindsley (1964) mostram que a existência de extensiva solução sólida entre magnetita (MT) e ilmenita (ILM) é duvidosa. Os autores sugerem que o conteúdo de $\mathrm{TiO}_{2}$ da magnetita estaria presente como ulvoespinélio (USP) e que as ilmenitas seriam formadas por oxidaçāo dessa fase. Portanto, na época de sua formação, as magnetitas titaníferas conteriam principalmente $\mathrm{Fe}_{2} \mathrm{TiO}_{2}$ (USP) em soluçāo sólida. Sob condiçōes de muito baixas fugacidades de oxigênio, o resfriamento até temperaturas abaixo do solvus (MT-USP) conduziria à exsolução de uma fase rica em ulvoespinélio nos planos (100) da magnetita; sob condiçōes de mais altas fugacidades de oxigênio, grande parte de ulvoespinélio, em soluçāo sólida, seria oxidada dire-

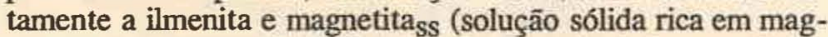
netita), a primeira podendo ocorrer como lamelas nos planos (111) da magnetita, ou como grânulos dispostos externa ou internamente à mesma (oxidação-exsolução sob a forma de grânulos externos ou internos); em pressōes de oxigênio intermediárias, seria possível o desenvolvimento tanto de intercrescimentos de ilmenita, por oxidação parcial, como de ulvoespinélio, por verdadeira exsolução. Assim, os intercrescimentos de ilmenita na magnetita resultariam, em grande escala, de fenômenos contemporâneos de oxidação e exsolução na solução sólida (MT-USP), durante o resfriamento. Esses intercrescimentos nāo seriam, portanto, verdadeiras exsoluçōes, mas, sim, oxidaçōes subsólidas do componente ulvoespinélio da soluçāo sólida (MT-USP) $)_{\text {SS }}$, resultando na formação de ilmenita pela seguinte reação:

$$
\begin{array}{ll}
\underset{6 F_{2} \mathrm{TiO}_{4}}{\mathrm{FiO}_{2}}+\mathrm{O}_{2} & =\underset{(\mathrm{MT})_{\mathrm{SS}}}{2 \mathrm{Fe}_{3} \mathrm{O}_{4}}+\underset{\text { (ILM) }}{6 \mathrm{FS}} \mathrm{FiO}_{3}
\end{array}
$$

Deve, no entanto, ser mencionado que uma parte dos intercrescimentos de ilmenita pode ter-se desenvolvido a partir de verdadeira exsoluçāo, como discutiu Anderson (1968). É observado que, enquanto as lamelas de ulvoespinélio seriam exsolvidas paralelamente aos planos (100) da magnetita hospedeira, as de ilmenita, formadas por oxidação-exsolução, orientam-se segundo os planos (111) da mesma. Esse arranjo ocorre se a oxidação-exsolução se dá a temperaturas elevadas (durante os primeiros estágios de resfriamento subsólido), quando a maior mobilidade dos íons favorece a quebra das lamelas do ulvoespinélio, originando uma orientação mais estável, como discutem Ramdohr (1953) e Reynolds (1980, 1983), entre outros. Esses autores mostram que, se a oxidaçāo das lamelas de ulvoespinélio ocorre a baixas temperaturas, as ilmenitas formadas preservam pseudomorficamente a textura original do mesmo, mas sāo orientadas cristalograficamente de modo que seus planos (0001) sejam paralelos aos planos (111) da magnetita.

No caso de Surubim, não foram observadas lamelas de ilmenita que preservem pseudomorficamente aquela microtextura. Isso pode sugerir ou que a oxidação do ulvoespinélio se deu a temperaturas suficientemente elevadas para permitir o rearranjo mais estável, ou que ocorreram processos simultâneos de oxidaçāo-exsoluçāo, formando diretamente os intercrescimentos de ilmenita.

Magnetita poiquiloblástica (Pr. 1, foto F), constituindo cristais de contornos irregulares, às vezes com bordas esfiapadas, englobando sulfetos finos e nāo apresentando nenhum dos intercrescimentos mencionados, também está presente em certas amostras. Às vezes encontra-se localizada ao lado de cristais de magnetita de contornos mais regulares com 

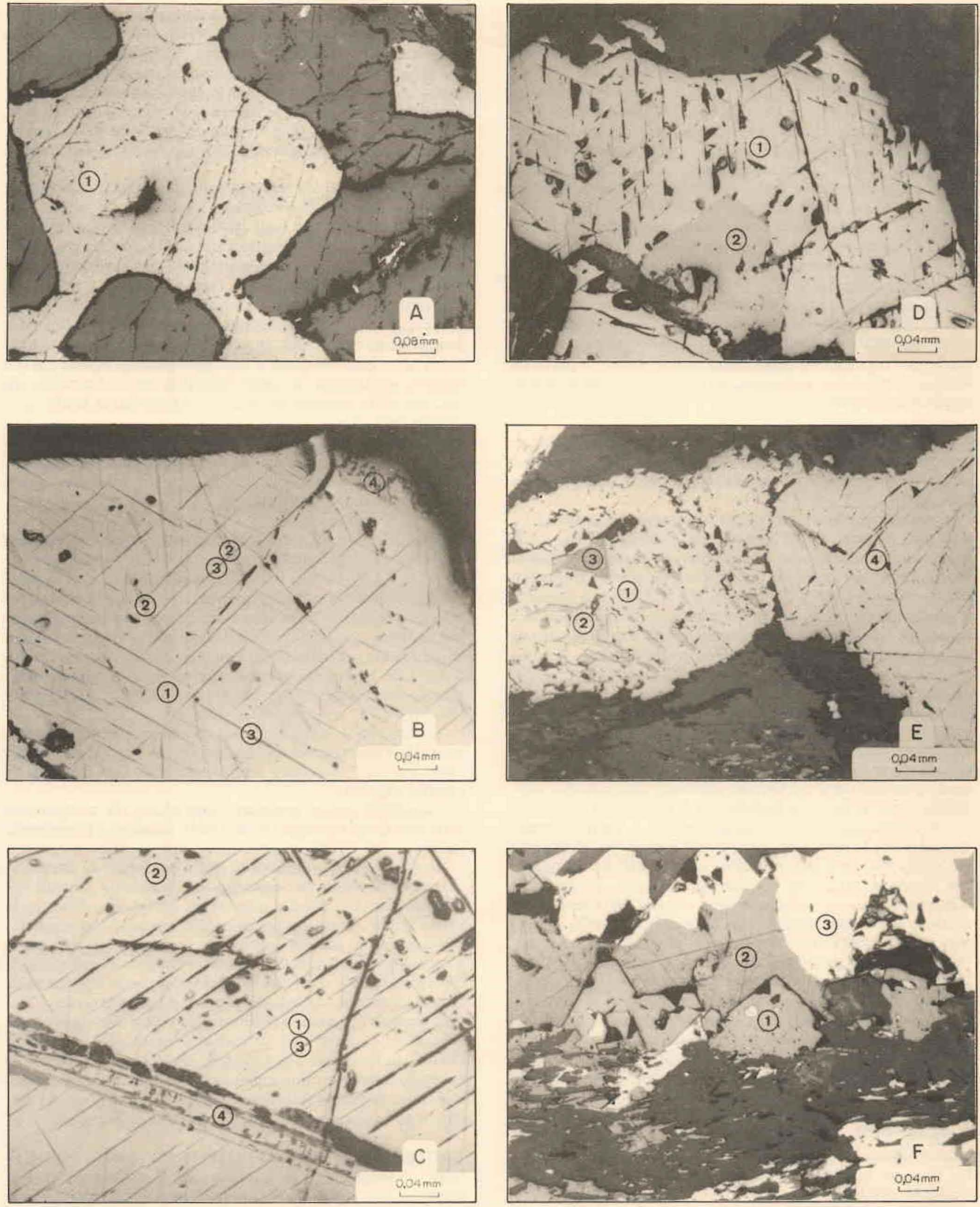

Prancha 1 - Fotomicrografias: A. granulito piroxenítico-magnetita (1), com lamelas finas de ilmenita e espinélio, associada a ortopiroxênio. Textura granoblástica. Nicóis paralelos. B. biotitito-magnetita (1) com lamelas finas de ilmenita (2) e de espinélio (3). Exsolução em grânulo externo de ilmenita leucoxenizada (4). Nicóis paralelos; C. biotitito-magnetita (1) com lamelas finas de ilmenita, em treliça (2) e de espinélio (3). Lamela larga de ilmenita leucoxenizada (4). Nicóis paralelos; D. biotitito-magnetita (1) com lamelas finas de ilmenita em treliça (cinza-claro) e de espinélio (cinza-escuro). Exsolução em grânulo interno de ilmenita (2). Nicóis paralelos; E. granulito hornblenda piroxenítico-magnetita poiquiloblástica (1) englobando calcopirita (2) e bornita (3); magnetita (4) com lamelas de ilmenita e espinélio, sem inclusōes de sulfetos. Nicóis paralelos. F. granulito piroxenítico-magnetita subédrica (1), englobando sulfetos finos, associada à bornita (2) e calcopirita (3). Nicóis paralelos. 
intercrescimentos, sugerindo, portanto, a existência de mais de uma etapa de formação desse mineral.

Localmente, em certos biotititos e rochas biotitizadas, ocorre um terceiro tipo de magnetita sob a forma de cristais finos (em média $0,05 \mathrm{~mm}$ ), euédricos a subédricos, podendo englobar sulfetos ( $\mathrm{Pr}$. 1, Foto F), constituídos essencialmente por $\mathrm{Fe}_{3} \mathrm{O}_{4}$ (Bello 1986). Diferenciam-se substancialmente da maioria das amostras, sugerindo serem provenientes de uma outra geraçāo, com temperaturas mínimas de formação muito baixas, conforme pode ser visto no diagrama de fases do sistema MT-USP (Buddington \& Lindsley 1964).

Cristais muito finos de magnetita podem ser vistos no interior de pseudomorfos de piroxênios, em parte constituídos por filossilicatos. Essas feições sugerem que sua formação se deu a partir dos piroxênios.

Em algumas amostras, a magnetita se apresenta martitizada (Pr. 2, Foto G), com desenvolvimento de finas lamelas de hematita segundo os planos (111) do mineral hospedeiro. A martitizaçāo, fenômeno de baixa temperatura, ocorre a partir de bordas ou em zonas fraturadas, havendo, no entanto, cristais totalmente afetados.

Ilmenita: Foram observados vários tipos texturais de ilmenita, caracterizados por diferentes dimensões, morfologias e modos de ocorrência, mostrando que sua formaçāo se deu em vários estágios.

Cristais anédricos a subédricos, de granulaçāo entre 0,01 e $0,08 \mathrm{~mm}$, podem ocorrem ora isolados, disseminados na rocha hospedeira, ora associados a magnetita, ou, ainda, constituindo "exsoluções" em grânulos internos e externos na magnetita (Pr. 1, Fotos B e D; Pr. 2, Fotos G, H e I). Quando associados à magnetita (Pr. 1, Foto G), os cristais de ilmenita possuem contornos regulares e bem definidos; por outro lado, cristais de contornos irregulares podem representar intercrescimentos em grânulos externos (Fotos B, H e I), sendo sua formaçāo devida, ao menos em parte, aos processos de oxidação e exsolução simultâneos durante o resfriamento subsólido.

Lamelas de ilmenita de dimensōes variáveis (comprimento entre 0,05 e $0,60 \mathrm{~mm}$ e espessuras entre 0,01 e $0,09 \mathrm{~mm}$ ) desenvolvem-se paralelamente aos planos (111) da magnetita, sendo comuns tanto os intercrescimentos denominados sanduíche, como treliça, por Buddington \& Lindsley (1964).

Os intercrescimentos em sanduíche ( $\mathrm{Pr}$. 2, Foto J), caracterizados por lamelas largas e bastante esparçadas de ilmenita em magnetita, tem sido atribuídos ou à cristalização simultânea desses minerais, ou a processos de oxidação-exsoluçāo contemporâneos da solução sólida original (Buddington \& Lindsley 1964, Haggerty 1976a, b). Reynolds (1983) sugere, com base em dados de microssonda e nas observaçōes texturais de amostras de 6 xidos dos doleritos do Karoo, que essas lamelas podem ser, em parte, formadas pela nucleação e crescimento de magnetita e ilmenita, havendo um desenvolvimento posterior desta última pelos processos de oxidaçãoexsolução que ocorrem durante o resfriamento.

Nos intercrescimentos em treliça constituídos por lamelas mais largas de ilmenita ( $\operatorname{Pr}$. 2, Fotos L e M), esta pode ter sido formada ou por verdadeira exsoluçāo, ou por oxidaçāo-exsolução da solução original (Anderson 1968, Reynolds 1981, Haggerty 1976a, b, Buddington \& Lindsley 1964). Os intercrescimentos em treliça de lamelas mais finas (Fotos B, C, D e L), por sua vez, ter-se-iam desenvolvido por processos de oxidaçāo-exsolução.

Deve ser enfatizado que Buddington \& Lindsley (op. cit.) consideram os seguintes tipos de intercrescimentos de ilmenita em magnetita, segundo a ordem crescente de oxidaçāo e difusāo: intercrescimentos em treliça, inicialmente de lamelas mais finas de ilmenita, seguidos pelos de lamelas mais largas; intercrescimentos em sanduíche de lamelas largas; e intercrescimentos sob a forma de grânulos internos e externos. No entanto, Haggerty (1976a) e Reynolds $(1981,1983)$, a partir do estudo das relações texturais e de dados de microssonda eletrônica de amostras de diversas rochas, argumentam que, na realidade, existem relaçōes inversas. Mostram que os intercrescimentos em grânulos seriam anteriores aos demais, tratando-se, em muitos casos, de inclusōes primárias; os intercrescimentos em treliça de lamelas mais finas, por outro lado, ocorreriam em condiçōes de altas fugacidades de oxigênio e baixas temperaturas, em situaçōes de menores mobilidades iônicas.

Transformaçōes de ilmenita em leucoxênio (Fotos B e H) foram encontradas principalmente em rochas de menor profundidade ou em zonas mais fraturadas; também ocorrem, localmente, nas outras amostras, demonstrando serem provenientes de fenômenos ora hidrotermais, ora supérgenos. Geralmente, a leucoxenizaçāo é acompanhada pela formação de interfaces silicosas (clorita, titanita e quartzo), que se desenvolvem normalmente nas zonas de transiçāo entre ilmenitas frescas e leucoxenizadas. Quando a leucoxenização afeta todo o cristal, o desenvolvimento das fases silicosas ocorre em seu interior, geralmente de modo irregular, sendo formados ora um, ora outro mineral, às vezes parecendo haver intercrescimentos entre eles.

Lamelas de hematita orientadas segundo planos (0001) da ilmenita também foram em alguns casos constatadas, tratando-se de verdadeira exsoluçāo (Buddington \& Lindsley 1964, Haggerty 1976a, b, entre outros).

Espinélios: Ocorrem, na maioria das vezes, como lamelas finas dispostas paralelamente aos planos (100) das magnetitas (Fotos B, C, D, E, H, J, L e M). Sāo geralmente menores que as lamelas de ilmenita. Seus comprimentos variam entre valores inferiores a 0,01 e $0,15 \mathrm{~mm}$ e suas espessuras normalmente são menores que $0,01 \mathrm{~mm}$. Dados de microssonda eletrônica, apresentados em Bello (1986), evidenciam variaçōes químicas acentuadas nas composiçōes desses espinélios, sendo constituídos essencialmente por $(\mathrm{Fe}, \mathrm{Mg}) \mathrm{Fe}_{2} \mathrm{O}_{4},(\mathrm{Fe}, \mathrm{Mg})_{2} \mathrm{TiO}_{4}$ e $\left(\mathrm{Fe}, \mathrm{Mg} \mathrm{Al}_{2} \mathrm{O}_{4}\right.$, em proporçōes variáveis.

Os espinélios também pociem constituir intercrescimentos irregulares em magnetita e ilmenita (Pr. 2, Foto I) ou ocorrer como grãos arredondados a subarredondados, na interface ilmenita/magnetita.

Espinélios verdes granulares intersticiais, de composiçōes próximas às da hercinita (Bello 1986), associados à magnetita, ilmenita e ortopiroxênio, estāo presentes em certas amostras.

Em certos casos, observa-se que a densidade de intercrescimentos lamelares de espinélio em magnetita diminui nas proximidades das lamelas mais largas de ilmenita. Esses espinélios seriam, portanto, posteriores à formaçāo das ilmenitas. Por outro lado, nâo são conclusivas as feiçōes que indicariam a cronologia relativa entre as lamelas finas de ilmenita e as de espinélio; muitas vezes, as lamelas de espinélio cortam as de ilmenita, havendo, no entanto também relaçōes inversas.

Enquanto Reynolds (1980) explica o desenvolvimento dos espinelios a partir de verdadeiras exsoluçöes, Haggerty $(1976 \mathrm{a}, \mathrm{b})$ considera sua formaçāo como resultado direto da oxidaçāo subsólida. Em ambos os casos, os autores consideram que o espinélio seria desenvolvido posteriormente à ilmenita, o que parece ocorrer com as amostras de Surubim.

\section{GEOTERMOMETRIA-BAROMETRIA DE OXIGÊ-} NIO Buddington \& Lindsley (1964) calibraram experimentalmente o geotermômetro-barômetro de oxigênio para as soluçōes sólidas magnetita-ulvoespinélio (MT-USP) ss e ilmenita-hematita (ILM-HEM) Ss, a partir da consideração de que as composiçōes dessas fases coexistentes são funções da temperatura $(\mathrm{T})$ e da fugacidade de oxigênio $\left(\mathrm{fO}_{2}\right)$. As incertezas do método, estimadas pelos autores, sâo de $\pm 50^{\circ} \mathrm{C}$ e \pm 1 unidade de $\log f \mathrm{O}_{2}$.

Powell \& Powell (1977) desnvolveram de modo independente um geotermômetro e um geobarômetro de oxigênio, 

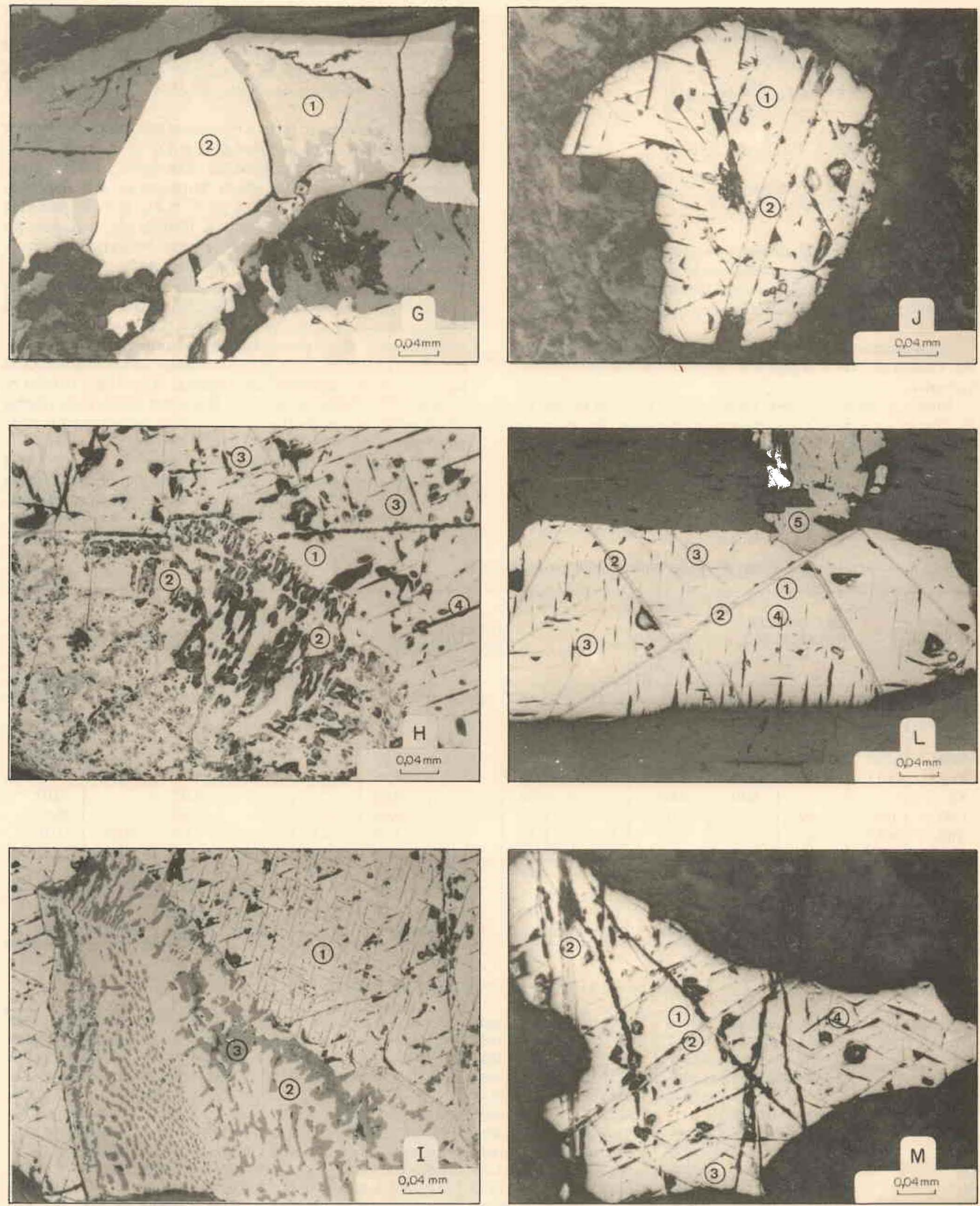

Prancha 2 - Fotomicrografias: G. granulito piroxenítico-magnetita martitizada (1)associada à ilmenita (2). Nicóis paralelos. H. biotitito-magnetita (1) com exsoluçāo em grânulo externo de ilmenita alterada, leucoxenizada (2) e com lamelas finas de ilmenita (3) $e$ de espinélio (4). Nicóis paralelos; I. biotitito-magnetita (1) com intercrescimentos finos de espinélio e ilmenita. Grânulo externo de ilmenita (2) com exsoluções irregulares de espinélio (3). Nicóis paralelos; J. biotitito-magnetita (1) com intercrescimentos de ilmenita-larga (2), lamelas finas (cinza-claro) pamela e de espinélio (cinza-escuro). Nicóis paralelos; L. biotita-ortopiroxênio gnaisse-magnetita (1) com intercrescimentos em treliça de lamelas largas (2) e finas (3) de ilmenita e de espinélio (4), associada a bornita (5). Nicóis paralelos. M. biotitito-magnetita (1) com intercrescimentos em treliça de ilmenita - lamelas largas (2) e finas (3) - e de espinélio (4). Nicóis paralelos. 
com base nos dados experimentais de Buddington \& Lindsley (1964). Utilizando formulações termodinâmicas, os autores chegaram às seguintes equaçōes:

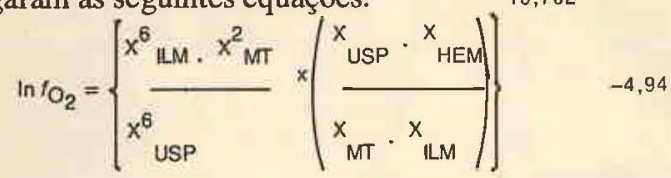

$$
\begin{aligned}
& T=\frac{-8155}{\ln K D-4,59} \text { em que } K D=\frac{X_{\text {USP }} \cdot X_{\text {HEM }}}{X_{\text {MT }} \cdot X_{\text {ILM }}}
\end{aligned}
$$

$\mathrm{X}_{\mathrm{USP}}=$ fração molar do ulvoespinélio na solução sólida (MT-USP) $\mathrm{X}_{\mathrm{MT}}=$ fração molar da magnetita na solução sólida (MT-USP) Ss $_{\mathrm{S}}$ $\mathrm{X}_{\mathrm{ILM}}=$ fraçāo molar da ilmenita na solução sólida (ILM-HEM) $\mathrm{X}_{\mathrm{HEM}}=$ fração molar da hematita na solução sólida (ILM-HEM)

As incertezas obtidas para $\mathrm{T}$ e $\log \mathrm{fO}_{2}$, a partir desse método, variam de $\pm 10^{\circ} \mathrm{C}$ a $; 40^{\circ} \mathrm{C} \mathrm{e} \mathrm{de} \pm 1$ a -3 unidades, respectivamente.

Maury \& D'Arco (1984) ressaltam que existem muitas dificuldades na avaliação das incertezas, pois elas dependem de um grande número de fatores, tais como: calibração experimental; escolha do modelo de soluçāo; presença de constituintes menores; heterogeneidades das composiçōes dos minerais analisados; quantidade de análises; métodos de cálculo; efeitos de alteração etc. Os autores concluem, portanto, que tais métodos geotermobarométricos deveriam ser baseados em um número razoável de análises químicas, e as incertezas presentes nos resultados seriam, provavelmente, da ordem de \pm $50^{\circ} \mathrm{C}$ e $\div 1$ unidade de $f_{\mathrm{O}}$, podendo ainda ser superiores, quando se consideram os efeitos relativos à heterogeneidade das composiçōes.

Como os óxidos de ferro e titânio sofrem reequilíbrios com as modificaçōes nas condiçōes de $\mathrm{T}$ e $\mathrm{fO}_{2}$, esses métodos devem ser utilizados com precauções. Sua aplicação direta, considerando as composições atuais da magnetita e da ilmenita, fornece, na realidade, valores de $\mathrm{T}$ e $f_{\mathrm{O}}$, dos reequilíbrios posteriores, registrando apenas a história do resfriamento subsólido, após o pico do metamorfismo. No entanto, se esses processos são interrompidos, é possível deduzir as composições das soluções sólidas originais pela reeintegração de ilmenitas secundárias em magnetita, combinando-se as proporções modais, expressas como porcentagens em peso, desses minerais. Por meio desse processo, muitos autores tem obtido temperaturas razoáveis tanto para a cristalização magmática como para o pico do metamorfismo regional (Thy 1982, Bohlen \& Essene 1977, Bohlen et al. 1980, Rollinson 1980), com valores semelhantes aos encontrados por outros métodos geotermométricos.

A formulação termodinâmica de Powell \& Powell (1977) para o geotermômetro-barômetro de oxigênio de Buddington \& Lindsley (1964) foi aplicada aos óxidos de Surubim, inicialmente a partir das composiçōes atuais das fases (Tabs. 1 e 2).

Tabela 1 - Composição química de magnetitas (dispersão de energia)

\begin{tabular}{l|c|c|c|c|c|r|r|r|r|r|r|r}
\hline \\
ROCHA
\end{tabular}

FÓRMULA ESTRUTURAL COM BASE EM 32 OXIGÊNIOS

\begin{tabular}{|c|c|c|c|c|c|c|c|c|c|c|c|c|c|}
\hline $\mathrm{Cr}$ & 0,4694 & 0,5532 & 0,6710 & 0,5186 & 1,8349 & 1,9606 & 1,7485 & 1,7352 & 1,6627 & 0,7365 & 0,7302 & 0,6183 & 0,6893 \\
\hline Mn & 0,0051 & 0,0121 & 0,0162 & - & 0,1008 & 0,1984 & 0,0918 & 0,1217 & 0,0815 & 0,0166 & 0,0027 & 0,0078 & 0,0126 \\
\hline $\mathrm{Fe}^{2+}$ & 7,9785 & 7,9889 & 8,0341 & 7,9970 & 8,1316 & 9,1068 & 7,9106 & 8,4212 & 7,9617 & 7,9650 & 7,9892 & 7,9934 & 8,1846 \\
\hline $\mathrm{Fe}^{3+}$ & 15,1433 & 15,3115 & 14,9021 & 15,4037 & 12.8693 & 9,9602 & 13,1177 & 12.0821 & 13,4322 & 14,8887 & 14,5877 & 15,1968 & 14.6349 \\
\hline K & - & - & 0,0047 & 0,0185 & - & 0,0185 & - & 0,0066 & - & - & 0,0104 & - & 0,0096 \\
\hline $\mathrm{Ca}$ & 0,0079 & 0,0078 & - & 0,0028 & - & 0,0293 & 0,0117 & 0,0046 & 0,0174 & - & 0,0101 & 0,0009 & 0,1764 \\
\hline $\mathrm{Ti}$ & 0,0341 & 0,0154 & 0,0811 & 0,0109 & 0,2755 & 1,4086 & 0,1751 & 0,6303 & 0,1022 & 0,0232 & 0,0146 & 0,0117 & 0,2566 \\
\hline $\mathrm{Na}$ & 0,0468 & - & 0,0732 & - & 0,0238 & 0,0636 & 0,0283 & 0,0805 & 0,0550 & 0,0246 & - & 0,0793 & - \\
\hline $\mathrm{Al}$ & 0,2745 & 0,1000 & 0,2275 & 0,0282 & 0,7383 & 1,2139 & 0,7430 & 0,8785 & 0,6776 & 0,2841 & 0,6209 & 0,1407 & 0,0562 \\
\hline Si & 0,0284 & - & 0,0171 & 0,0212 & - & 0,0122 & 0,0270 & 0,0189 & - & 0,0376 & 0,0236 & - & 0,0153 \\
\hline $\mathbf{M g}$ & 0,0282 & 0,0122 & 0,0122 & - & 0,0397 & 0,0794 & 0,1524 & 0,0656 & 0,0475 & 0,0195 & 0,0068 & - & 0,0062 \\
\hline $\mathrm{XFe}$ & 0,9965 & 0,9985 & 0,9985 & 1,0000 & 0,9952 & 0,9915 & 0,9813 & 0,9924 & 0,9941 & 0,9976 & 0,9991 & 1,0000 & 0,9992 \\
\hline $\mathrm{FeCr}_{2} \mathrm{O}_{4}$ & 2,92 & 3,36 & 4,06 & 3,16 & 11,23 & 10,15 & 10,72 & 10,67 & 10,15 & 4,45 & 4,52 & 3,85 & 4,11 \\
\hline $\mathrm{MgAl}_{2} \mathrm{O}_{4}$ & 0,14 & 0,14 & 0,14 & - & 0,28 & 0,28 & 1,14 & 0,44 & 0,28 & 0,14 & - & - & - \\
\hline $\mathrm{FeAl}_{2} \mathrm{O}_{4}$ & 1,05 & 0,35 & 0,88 & 0,17 & 3,31 & 2,80 & 2,26 & 3,70 & 2,80 & 1,21 & 2,98 & 0,71 & 0,36 \\
\hline $\mathrm{MnFe}_{2} \mathrm{O}_{4}$ & - & 0,24 & 0,24 & - & 1,18 & 0,95 & 1,18 & 1,67 & 0,95 & 0,24 & - & - & 0,24 \\
\hline $\mathrm{Fe}_{2} \mathrm{TiO}_{4}$ & 0,45 & 0,22 & 0,90 & 0,22 & 3,36 & 1,35 & 2,24 & 7,71 & 1,35 & 0,22 & 0,22 & 0,22 & 3,19 \\
\hline $\mathrm{Fe}_{3} \mathrm{O}_{4}$ & 95,44 & 95,69 & 93,78 & 96,45 & 80,63 & 84,47 & 82,48 & 75,81 & 84,47 & 93,75 & 92,28 & 95,22 & 92,10 \\
\hline $\mathrm{TiO}_{2} / \mathrm{FeO}+\mathrm{F}_{2} \mathrm{O}_{3}$ & 0,0016 & 0,0007 & 0,0037 & 0,0005 & 0,0137 & 0,0777 & 0,0086 & 0,0321 & 0,0050 & 0,0010 & 0,0006 & 0,0005 & 0,0117 \\
\hline
\end{tabular}


Tabela 2 - Composição química de ilmetitas (dispersão de energia)

\begin{tabular}{|c|c|c|c|c|c|c|c|c|c|c|c|c|c|}
\hline \multirow{2}{*}{$\begin{array}{l}\text { ROCHA } \\
\text { Amostra }\end{array}$} & \multicolumn{3}{|c|}{$\begin{array}{c}\text { GRANULITO } \\
\text { NORÍTICO } \\
\mathbf{U}_{3}\end{array}$} & \multirow{2}{*}{$\begin{array}{c}\begin{array}{c}\text { GRANU- } \\
\text { LITO } \\
\text { GABRO } \\
\text { NORÍ- } \\
\text { TICO }\end{array} \\
44 / 40\end{array}$} & \multicolumn{5}{|c|}{$\begin{array}{l}\text { GRANULITO } \\
\text { PIROXENITICO }\end{array}$} & \multicolumn{4}{|c|}{ BIOTITITOS } \\
\hline & $26 \mathrm{a} / 57$ & $26 \mathrm{a} / 61$ & $26 a / 63$ & & $46 / 44$ & $46 / 46$ & $46 / 47$ & $46 / 49$ & $46 / 50$ & $45 / 33$ & $45 / 36$ & $45 / 38$ & $47 / 70$ \\
\hline $\mathrm{Cr}_{2} \mathrm{O}_{3}$ & 0,12 & 0,11 & 0,11 & 0,10 & 0,10 & 4,74 & 0,32 & 0,07 & 0,11 & 0,08 & 0,21 & 0,10 & 0,12 \\
\hline $\mathrm{MnO}$ & 4,20 & 3,85 & 4,21 & 2,41 & 3,12 & 2,49 & 3,90 & 3,37 & 3,72 & 3,59 & 3,74 & 3,67 & 2,38 \\
\hline $\mathrm{K}_{2} \mathrm{O}$ & - & - & - & - & - & 0,01 & & 0,09 & - & 0,04 & - & - & 0,03 \\
\hline $\mathrm{CaO}$ & 0,02 & - & 0,01 & 0,02 & 0,03 & - & $\begin{array}{r}0,02 \\
52,61\end{array}$ & 0,10 & - & - & 0,01 & 0,05 & - \\
\hline $\mathrm{TiO}_{2}$ & 51,55 & 51,94 & 51,14 & 50,63 & 52,18 & 35,14 & 52,61 & 46,52 & 52,04 & 51,77 & 52,54 & 52,23 & 52,40 \\
\hline $\mathrm{Na}_{2} \mathrm{O}$ & 0,15 & - & 0,03 & 0,05 & 0,01 & 0,03 & 0,02 & 0,90 & 0,09 & 0,04 & - & 0,06 & 0,02 \\
\hline $\mathrm{Al}_{2} \mathrm{O}_{3}$ & - & - & - & 0,01 & - & 13,33 & - & 0,09 & - & - & - & - & - \\
\hline $\mathrm{SiO}_{2}$ & - & - & - & - & 0,04 & 0,03 & 0,06 & 0,33 & - & - & - & - & 0,01 \\
\hline
\end{tabular}

FÓRMULA ESTRUTURAL COM BASE EM 6 OXIGÊNIOS

\begin{tabular}{|c|c|c|c|c|c|c|c|c|c|c|c|c|c|}
\hline $\mathrm{Cr}$ & 0,0047 & 0,0045 & 0,0043 & 0,0039 & 0,0041 & 0,1766 & 0,0127 & 0,0028 & 0,0044 & 0,0030 & 0,0082 & 0,0040 & 0,0048 \\
\hline $\mathrm{Mn}$ & 0,1801 & 0,1643 & 0,1796 & 0,1022 & 0,1327 & 0,0993 & 0,1654 & 0,1480 & 0,1585 & 0,1515 & 0,1593 & 0,1547 & 0,1004 \\
\hline $\mathrm{Fe}^{2+}$ & 1,7812 & 1,7983 & 1,7518 & 1,8009 & 1,8222 & 1,3965 & 1,8048 & 1,6300 & 1,7902 & 1,7837 & 1,8257 & 1,7952 & 1,8614 \\
\hline $\mathrm{Fe}^{3+}$ & 0,0631 & 0,0597 & 0,1222 & 0,1768 & 0,0523 & 0,2796 & 0,0143 & 0,2995 & 0,0541 & 0,1134 & 0,0163 & 0,0838 & 0,0727 \\
\hline K & & & & & & 0,0009 & 0,0002 & 0,0061 & & 0,0028 & & & 0,0022 \\
\hline $\mathrm{Ca}$ & 0,0009 & & 0,0005 & 0,0011 & 0,0014 & & 0,0011 & 0,0054 & 0,0002 & & 0,0007 & 0,0026 & \\
\hline $\mathrm{Ti}$ & 1,9624 & 1,9670 & 1,9353 & 1,9074 & 1,9692 & 1,2466 & 1,9815 & 1,8153 & 1,9683 & 1,9398 & 1,9860 & 1,9536 & 1,9594 \\
\hline $\mathrm{Na}$ & 0,0146 & & 0,0026 & 0,0051 & 0,0013 & 0,0030 & 0,0020 & 0,0909 & 0,0084 & 0,0043 & & 0,0053 & 0,0017 \\
\hline Al & & & & 0,0003 & & 0,7411 & & 0,0052 & & & & & \\
\hline $\mathrm{Si}$ & & & & & 0,0018 & 0,0015 & 0,0030 & 0,0173 & 0,0002 & 0,0002 & & & 0,0004 \\
\hline $\mathrm{Mg}$ & 0,0035 & 0,0067 & 0,0061 & 0,0064 & 0,0162 & 0,2096 & 0,0177 & 0,0413 & 0,0218 & 0,0062 & 0,0052 & 0,0057 & \\
\hline $\mathrm{XFe}$ & 0,9982 & 0,9966 & 0,9969 & 0,9966 & 0,9918 & 0,8771 & 0,9911 & 0,9773 & 0,9890 & 0,9968 & 0,9974 & 0,9971 & 1,0000 \\
\hline $\mathrm{MnTiO}_{3}$ & 8,95 & 8,14 & 8,88 & 5,10 & 6,62 & 5,19 & 8,29 & 7,59 & 7,84 & 7,61 & 7,98 & 7,76 & 5,06 \\
\hline $\mathrm{MgTiO}_{3}$ & 0,12 & 0,24 & 0,24 & 0,24 & 0,60 & 8,75 & 0,72 & 1,64 & 0,84 & 0,24 & 0,24 & 0,24 & \\
\hline $\mathrm{Fe}_{2} \mathrm{O}_{3}$ & 1,67 & 1,58 & 3,22 & 4,66 & 1,43 & 7,74 & 0,38 & 8,04 & 1,44 & 3,00 & 0,43 & 2,22 & 1,92 \\
\hline $\begin{array}{l}\mathrm{FeTiO}_{3} \\
\mathrm{FeCr}_{2} \mathrm{O}_{4}\end{array}$ & 89,26 & 90,04 & 87,66 & 90,00 & 91,35 & $\begin{array}{r}49,35 \\
6,60\end{array}$ & 90,61 & 82,73 & 89,88 & 89,16 & 91,35 & 89,79 & 93,02 \\
\hline $\mathrm{FeAl}_{2} \mathrm{O}_{4}$ & & & & & & 22,37 & & & & & & & \\
\hline
\end{tabular}

Para a obtenção das fraçōes molares de USP, MT, ILM e HEM, por meio de análises químicas, utilizou-se o método descrito por Buddington \& Lindsley (1964), que considera a influência dos constituintes menores sempre presentes nesses minerais.

No caso das magnetitas, o $\mathrm{Al}, \mathrm{Cr}, \mathrm{Mg}$ e $\mathrm{Mn}$ são considerados como responsáveis pela formaçāo da hercinita $\left(\mathrm{FeAl}_{2} \mathrm{O}_{4}\right)$, cromita $\left(\mathrm{FeCr}_{2} \mathrm{O}_{4}\right)$ e espinélio $\left(\mathrm{MgAl}_{2} \mathrm{O}_{4}\right.$ e galaxita $\left(\mathrm{MnAl}_{2} \mathrm{O}_{4}\right)$, respectivamente. Os constituintes menores são, então agrupados como $\mathrm{RO}$ e $\mathrm{R}_{2} \mathrm{O}_{3}$ e combinados na fórmula do espinélio $\mathrm{Ro} \cdot \mathrm{R}_{2} \mathrm{O}_{3}$. O $\mathrm{SiO}_{2}$ é calculado como $2 \mathrm{RO} \cdot \mathrm{SiO}_{2}$. Em geral, existe ou $\mathrm{RO}$, ou $\mathrm{R}_{2} \mathrm{O}_{3}$ em excesso. Se $\mathrm{RO}$ está em excesso, ele é distribuído igualmente entre $\mathrm{RO} \cdot \mathrm{Fe}_{2} \mathrm{O}_{3}$ RO. $\mathrm{TiO}_{2}$, descartando-se as quantidades que entram nessas fórmulas. Se $\mathrm{R}_{2} \mathrm{O}_{3}$ está em excesso, caso das magnetitas de Surubim, essa quantidade é combinada e descartada como $\mathrm{FeO} \cdot \mathrm{R}_{2} \mathrm{O}_{3}$. O $\mathrm{TiO}_{2}$ remanescente é combinado com $2 \mathrm{FeO}$ para formar o ulvoespinélio, e o que resta de $\mathrm{FeO}$ é associado a $\mathrm{Fe}_{2} \mathrm{O}_{3}$, formando a magnetita. Posteriormente, $\mathrm{Fe}_{2} \mathrm{TiO}_{4}$ e $\mathrm{Fe}_{3} \mathrm{O}_{4}$ são recalculados para $100 \%$

No caso das ilmenitas, $\mathrm{Al}, \mathrm{Mg}$ e $\mathrm{Mn}$ são considerados, respectivamente, como responsáveis pela formaçāo de coríndon $\left(\mathrm{Al}_{2} \mathrm{O}_{3}\right)$, geikielita $\left(\mathrm{MgTiO}_{3}\right)$ e pirofanita $\left(\mathrm{MnTiO}_{3}\right)$, sendo os constituintes menores RO agrupados como RO.TiO 2 e descartados. Os constituintes $\mathrm{R}_{2} \mathrm{O}_{3}$ sāo também descartados. $\mathrm{O}$ $\mathrm{TiO}_{2}$ restante é combinado com FeO formando a ilmenita, podendo-se obter $\mathrm{FeO}$ adicional, quando necessário a partir de $\mathrm{Fe}_{2} \mathrm{O}_{3}$. O Fe $\mathrm{O}_{2} \mathrm{O}_{3}$ remanescente é calculado como hematita. Os valores de $\mathrm{FeTiO}_{3}$ e $\mathrm{Fe}_{2} \mathrm{O}_{3}$ são, então, recalculados para $100 \%$.

As frações molares assim obtidas foram utilizadas nas equações 2 e 3 , tendo sido determinadas temperaturas variando entre $780^{\circ} \mathrm{C}$ e $237^{\circ}$ e $\log \mathrm{fO}_{2}$ situado entre $-13,37$ e $-39,36$ (Tab. 3 e Fig. 1). Esses valores sāo indicativos dos reequilíbrios subsólidos a partir de temperaturas maiores relacionadas ao pico do metamorfismo granulítico. Observe-se que, neste caso, foram incluídas algumas ilmenitas cujas relaçōes com magnetitas parecem duvidosas, podendo tratar-se, na realidade, de intercrescimentos granulares, pois seus contatos nem sempre são regulares e retilíneos. No entanto, para efeito do estudo dos reequilibrios subsólidos posteriores ao pico do metamorfismo, os valores obtidos, a partir dessas amostras, podem ser utilizados sem problemas.

O diagrama $-\log f_{\mathrm{O}_{2}} \times \mathrm{T}$ (Fig. 1a) mostra a curva de resfriamento a partir da temperatura de $780^{\circ} \mathrm{C}$. Observa-se nesse diagrama que, nas regiōes de mais altas temperaturas, os 
Tabela 3 - Geotermometria/barometria de oxigênio (óxidos de Fe e Ti)

\begin{tabular}{|c|c|c|c|c|c|c|c|c|}
\hline (MT) & Amostra & (ILM) & $\mathbf{X}_{\text {USP }}$ & $\underset{M T}{x_{M T}}$ & $\mathrm{X}_{\text {HEM }}$ & $\frac{\mathbf{X}_{\text {ILM }}}{(\text { Ilmenita }}$ & $\mathbf{T}\left({ }^{\circ} \mathrm{C}\right)$ & $\log f \mathrm{O}_{2}$ \\
\hline $26 \mathrm{a} / 58$ & - & $26 \mathrm{a} / 57$ & 0,48 & 99,52 & 1,84 & 98,16 & 314 & $-31,56$ \\
\hline $26 a / 60$ & - & $26 a / 61$ & 0,23 & 99,77 & 1,72 & 98,28 & 281 & $-33,39$ \\
\hline $26 \mathrm{a} / 64$ & - & $26 a / 63$ & 0,95 & 99,05 & 3,55 & 96,45 & 377 & $-27,06$ \\
\hline $44 / 41$ & - & $44 / 40$ & 0,23 & 99,77 & 4,92 & 95,08 & 326 & $-28,44$ \\
\hline $46 / 43$ & _- & $46 / 44$ & 0,39 & 96,10 & 1,55 & 98,45 & 410 & $-27,96$ \\
\hline $46 / 45$ & - & $46 / 46$ & 21,40 & 78,60 & 13,56 & 86,44 & 780 & $-13,37$ \\
\hline $46 / 48$ & - & $46 / 47$ & 2,60 & 97,40 & 0,42 & 99,58 & 323 & $-34,93$ \\
\hline $46 / 51$ & - & $46 / 49$ & 9,10 & 90,90 & 8,86 & 91,14 & 611 & $-17,75$ \\
\hline $46 / 52$ & - & $46 / 50$ & 1,57 & 98,43 & 1,58 & 98,42 & 361 & $-29,81$ \\
\hline $46 / 51,52$ & - & $46 / 49,50$ & 5,26 & 94,74 & 5,11 & 94,89 & 511 & $-21,67$ \\
\hline $45 / 34$ & _- & $45 / 33$ & 0,23 & 99,77 & 3,25 & 96,75 & 307 & $-30,40$ \\
\hline $45 / 37$ & - & $45 / 36$ & 0,24 & 99,76 & 0,47 & 99,53 & 237 & $-39,36$ \\
\hline $45 / 34,37$ & - & $45 / 33,36$ & 0,24 & 99,76 & 1,87 & 98,13 & 286 & $-32,91$ \\
\hline $45 / 39$ & - & $45 / 38$ & 0,23 & 99,77 & 2,41 & 97,59 & 295 & $-31,81$ \\
\hline $47 / 71$ & _- & $47 / 70$ & 3,35 & 96,65 & 2,02 & 97,98 & 416 & $-27,05$ \\
\hline
\end{tabular}
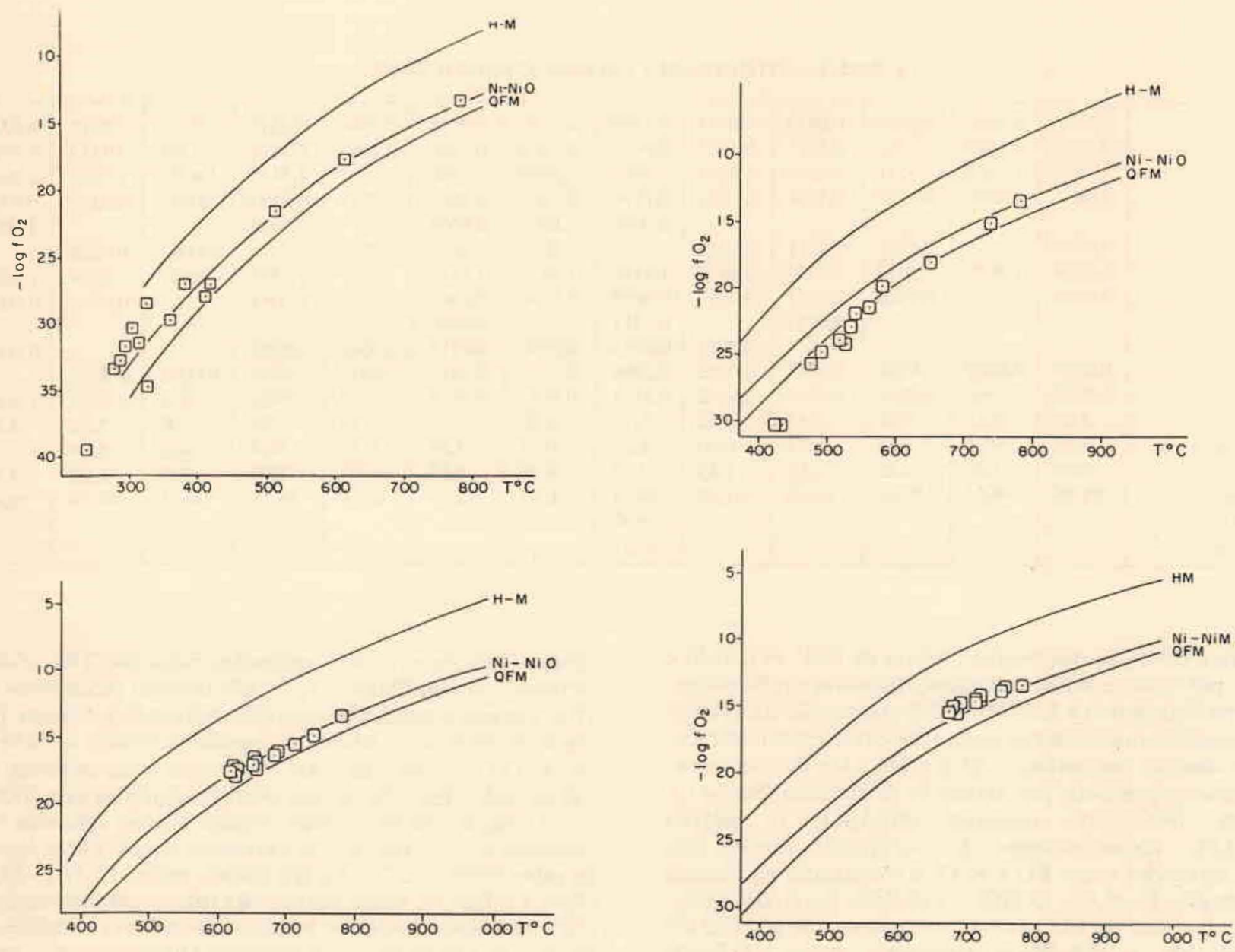

Figura $I$ - Diagramas de variação de-log $\mathrm{f}_{2}$ em função de $T$ para magnetitas e ilmenitas coexistentes de amostras de Surubim. Cálculos realizados a partir da formulaçāo termodinâmica de Powel \& Powell (1977) para o geotermômetrolbarômetro de Buddington \& Lindsley (1964) tendo sido utilizadas: a. composiçöes atualmente encontradas nas fases coexistentes; b. composiçöes obtidas a partir da reintegração das lamelas de ilmenita na magnetita hospedeira; c. composiçóes obtidas a partir da reintegração das lamelas de ilmenita nas magnetitas, com estimativas das composições originais das ilmenitas, considerando-se as ilmenitas mais ricas em $\mathrm{Fe}_{2} \mathrm{O}_{3}$ como as menos modificadas com o resfriamento; d. idem a c, utilizando-se o valor fixo da relaçāo $\mathrm{Fe}_{\text {total }} / \mathrm{TiO} \mathrm{O}_{2}$ de ilmenitas mais ricas em hematita como o representativo da composiçāo original daquele mineral. Curvas-tampāo $Q-F-M, N i-N i O$ e $H$ - $M$ calculadas a $8 \mathrm{kBar}$ a partir dos dados de Eugster \& Wones (1962) 
valores de $-\log \mathrm{fO}_{2}$ estāo situados próximos à curva tampāo quartzo-faialita-magnetita (QFM), para pressões totais de 8 kbar. Nas outras regiōes, as determinaçôes estão fora do intervalo de calibraçāo de Buddington \& Lindsley (1964); esses valores sugerem, no entanto, que os reequilíbrios subsólidos cessaram a temperaturas bastante baixas. Neste caso, os pontos se apresentam mais dispersos aproximando-se da curva-tampāo hematita-magnetita (HM). Isso pode ser indicativo de reequilíbrios em diferentes condiçōes, possivelmente governados pela introdução diferencial de fluidos oxidantes em zonas de fraqueza.

As curvas-tampão foram consideradas a $8 \mathrm{kbar}$ (correçōes realizadas com base nos dados de Eugster \& Wones 1962), pois o método geobarométrico de Harley \& Green (1982) forneceu, para a regiāo de Surubim, pressões totais médias em torno desse valor (Bello 1986).

Numa segunda etapa, foi realizada, quando possível, a reintegração das ilmenitas secundárias na magnetita hospedeira, a partir de suas proporçōes modais (Tab. 4), numa tentativa de melhor estabelecer as condições do pico do metamorfismo. Se for valida a afirmação de que os intercrescimentos de ilmenita e as magnetitas hospedeiras constituíram, anteriormente, soluçōes sólidas de (USP-MT) ss, entāo, a partir da reintegração, com a obtenção das composiçōes originais, essas condiçōes poderāo ser mais precisamente estabelecidas.

Neste caso, foram eliminados os pares magnetita/ilmenita de relaçōes texturais duvidosas, uma vez que se pretende determinar $\mathrm{T}$ e $\mathrm{fO}_{2}$ prevalescentes durante o pico do metamorfismo e não a história do resfriamento subsólido posterior.

A reintegração das ilmenitas secundárias foi realizada supondo-se, inicialmente, que esse mineral não tenha sofrido modificaçōes com o resfriamento. As composições das magnetitas reintegradas resultantes se encontram na tabela 4. Com esse procedimento, foram obtidas temperaturas variando entre $780^{\circ} \mathrm{C}$ e $425^{\circ} \mathrm{C}$ e $\log \mathrm{fO}_{2}$ entre $-13,37$ e $-30,31$ (Tab. 5 e Fig. 1b), havendo uma diminuição nos intervalos de valores determinados anteriormente. Os pontos no diagrama apresentam, no entanto, grandes dispersōes, provavelmente devido aos diferentes graus de oxidaçāo da ilmenita. A partir de estudos sobre a cinética das reaçōes de oxidaçāo e redução, Hammond
\& Taylor (1982) sugerem que as composiçōes químicas de magnetitas e ilmenitas podem apenas permanecer imutáveis, para certas rochas ígneas submetidas a rápido resfriamento. No caso de rochas metamórficas de alto grau, portanto, é de esperar variaçōes composicionais nas duas fases, principalmente em regiōes, como a de Surubim, submetidas a intenso retrometamorfismo.

Considerando-se então a modificação da ilmenita com o resfriamento, devido à exsolução de hematita, e aos reequilíbrios com magnetitas titaníferas, minerais silicáticos ou mesmo fluidos percolantes, observou-se a necessidade de se estabelecer sua composição original.

A composição original da ilmenita foi obtida apenas de modo aproximado devido às dificuldades em se estabelecer com precisão os parâmetros envolvidos.

Primeiramente, determinou-se essa composição considerando-se que as ilmenitas mais ricas em $\mathrm{Fe}_{2} \mathrm{O}_{3}$ (Amostra $46 / 46$, Tab. 2), seriam as representativas das que sofreram menos modificaçōes com o resfriamento. As composiçōes das outras amostras foram recalculadas com base nesse máximo valor de $\mathrm{F}_{2} \mathrm{O}_{3}$ e, posteriormente, utilizadas para efeito de reintegração (Tabs. 6 e 7). Os resultados obtidos por esse método podem ser vistos na tabela 8 e figura $1 c$, na qual se observa que os pontos representativos da maioria das amostras situam-se próximos à curva QFM a 8 kbar de pressāo total, não havendo grandes dispersöes. Os novos valores de temperatura e de $\log f \mathrm{O}_{2}$ variam de $780^{\circ} \mathrm{C}$ a $617^{\circ} \mathrm{C}$ e de $-13,37$ a $-17,68$, respectivamente, num intervalo que melhor define as condiçōes metamórficas.

Posteriormente, os cálculos foram realizados utilizando-se um valor fixo da relaçāo $\mathrm{FeO}$ total/ $\mathrm{TiO}_{2}$ de ilmenitas mais ricas em hematita (média das amostras $46 / 46$ e $46 / 49$, na tabela 2), considerando-se que essa razão seja representativa da composiçăo original daquele mineral. Esse procedimento foi utilizado por Thy (1982), que obteve, desse modo, uma boa aproximação das condiçōes de cristalização do complexo de Fongen-Hyllingen, Noruega.

As composiçōes das ilmenitas, desse modo recalculadas, e das magnetitas equivalentes reintegradas, encontram-se nas tabelas 9 e 10 . Os valores de temperatura e de $\log \mathrm{fO}_{2}$, obtidos

Tabela 4 - Composição de magnetitas com reintegração de ilmenitas secundárias

\begin{tabular}{|c|c|c|c|c|c|c|c|c|c|c|c|c|}
\hline \multirow{3}{*}{$\begin{array}{l}\text { ROCHA } \\
\text { Amostra }\end{array}$} & \multicolumn{2}{|c|}{$\begin{array}{c}\text { GRANULITO } \\
\text { NORITICO } \\
\mathbf{U}_{3}\end{array}$} & \multirow{2}{*}{\begin{tabular}{|c|} 
GRANU- \\
LITO \\
GABRO \\
NORÍ- \\
TICO \\
$44 / 41$ \\
\end{tabular}} & \multicolumn{5}{|c|}{$\begin{array}{l}\text { GRANULITO } \\
\text { PIROXENITICO }\end{array}$} & \multicolumn{4}{|c|}{ BIOTITITOS } \\
\hline & $26 \mathrm{a} / 58$ & $26 \mathrm{a} / 64$ & & $46 / 43$ & $46 / 48$ & $46 / 51$ & $46 / 52$ & $46 / 51,52$ & $45 / 34$ & $45 / 37$ & $45 / 34,37$ & $47 / 39$ \\
\hline & 7 & 6 & 8 & 4 & 9 & 10 & 10 & 10 & 9 & 9 & 9 & 9 \\
\hline $\mathrm{Cr}_{2} \mathrm{O}_{3}$ & 1,79 & 2,60 & 1,96 & 7,34 & 6,72 & 6,49 & 6,21 & 6,36 & 2,80 & 2,76 & 2,78 & 2,31 \\
\hline $\mathrm{MnO}$ & 0,31 & 0,31 & 0,19 & 0,49 & 0,68 & 0,76 & 0,66 & 0,72 & 0,37 & 0,35 & 0,37 & 0,36 \\
\hline $\mathrm{FeO}$ & 31,66 & 31,84 & 31,88 & 32,51 & 32,49 & 33,49 & 32,33 & 32,91 & 32,44 & 32,22 & 32,34 & 31,96 \\
\hline $\mathrm{Fe}_{2} \mathrm{O}_{3}$ & 60,71 & 60,68 & 61,27 & 54,18 & 52,76 & 48,16 & 52,77 & 50,47 & 59,68 & 57,50 & 58,60 & 59,55 \\
\hline $\mathrm{K}_{2} \mathrm{O}$ & - & 0,01 & 0,05 & - & - & 0,03 & 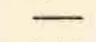 & 0,01 & - & 0,03 & 0,02 & - \\
\hline $\mathrm{CaO}$ & 0,02 & - & 0,01 & - & 0,04 & 0,02 & 0,05 & 0,03 & - & 0,03 & 0,02 & - \\
\hline $\mathrm{TiO}_{2}$ & 3,75 & 3,40 & 4,10 & 3,25 & 5,43 & 7,13 & 5,61 & 6,37 & 4,75 & 4,78 & 4,76 & 4,75 \\
\hline $\mathrm{Na}_{2} \mathrm{O}$ & 0,08 & 0,11 & & 0,04 & 0,05 & 0,22 & 0,09 & 0,16 & 0,05 & & 0,02 & 0,12 \\
\hline $\mathrm{Al}_{2} \mathrm{O}_{3}$ & 0,70 & 0,59 & 0,07 & 1,99 & 1,91 & 2,21 & 1,69 & 1,94 & 0,73 & 1,57 & 1,15 & 0,35 \\
\hline $\mathrm{SiO}_{2}$ & 0,08 & 0,06 & 0,06 & - & 0,09 & 0,08 & 一 & 0,05 & 0,11 & 0,07 & 0,09 & - \\
\hline $\mathrm{MgO}$ & 0,06 & 0,03 & 0,01 & 0,10 & 0,33 & 0,18 & 0,12 & 0,15 & 0,05 & 0,02 & 0,04 & 0,01 \\
\hline Total & 99,16 & 99,63 & 99,60 & 99,90 & 100,50 & 98,77 & 99,53 & 99,17 & 100,98 & 99,33 & 100,19 & 99,41 \\
\hline
\end{tabular}


Tabela 5 - Geotermometria/barometria de oxigênio (óxidos de Fe e Ti, com reintegração de ilmenitas secundárias em magnetita)

\begin{tabular}{|c|c|c|c|c|c|c|c|c|c|}
\hline (MT) & Amostra & (ILM) & (\% ILM) & ${ }_{\text {USP }}^{\mathrm{X}}$ & $\underset{M T}{\text { tita }_{\mathrm{SS}}}$ & $\mathrm{X}_{\text {HEM }}$ & ${ }_{\text {ILM }}^{\left.\mathbf{X}_{\text {IImenita }}\right)_{\text {SS }}}$ & $\mathbf{T}\left({ }^{\circ} \mathbf{C}\right)$ & $\log f \mathrm{O}_{2}$ \\
\hline $26 \mathrm{a} / 58$ & - & $26 \mathrm{a} / 57$ & 7 & 11,32 & 88,67 & 1,77 & 98,23 & 492 & $-24,85$ \\
\hline $26 \mathrm{a} / 64$ & - & $26 a / 63$ & 6 & 10,38 & 89,62 & 3,55 & 96,45 & 539 & $-21,80$ \\
\hline $44 / 41$ & - & $44 / 40$ & 8 & 12,14 & 87,86 & 4,91 & 95,09 & 582 & $-19,87$ \\
\hline $46 / 43$ & - & $46 / 44$ & 4 & 10,88 & 89,12 & 1,48 & 98,52 & 476 & $-25,79$ \\
\hline $46 / 45$ & - & $46 / 46$ & 0 & 21,40 & 78,60 & 13,56 & 86,44 & 780 & $-13,37$ \\
\hline $46 / 48$ & - & $46 / 47$ & 9 & 17,95 & 82,05 & 0,42 & 99,58 & 431 & $-30,33$ \\
\hline $46 / 51$ & - & $46 / 49$ & 10 & 24,22 & 75,78 & 8,81 & 91,19 & 738 & $-15,10$ \\
\hline $46 / 52$ & - & $46 / 50$ & 10 & 18,51 & 81,49 & 1,57 & 98,43 & 526 & $-24,09$ \\
\hline $46 / 51,52$ & - & $46 / 49,50$ & 10 & 21,39 & 78,61 & 5,10 & 94,90 & 652 & $-18,11$ \\
\hline $45 / 34$ & - & $45 / 33$ & 9 & 14,24 & 85,76 & 3,25 & 96,75 & 561 & $-21,40$ \\
\hline $45 / 37$ & - & $45 / 36$ & 9 & 14,97 & 85,03 & 0,47 & 99,53 & 425 & $-30,31$ \\
\hline $45 / 34,37$ & - & $45 / 33,36$ & 9 & 14,78 & 85,22 & 1,87 & 98,13 & 518 & $-23,90$ \\
\hline $45 / 39$ & - & $45 / 38$ & 9 & 14,21 & 85,79 & 2,40 & 97,60 & 535 & $-22,84$ \\
\hline
\end{tabular}

Tabela 6 - Composição de magnetitas com reintegração de ilmenitas secundárias recalculadas (com base nas ilmenitas mais ricas em $\mathrm{Fe}_{2} \mathrm{O}_{3}$ )

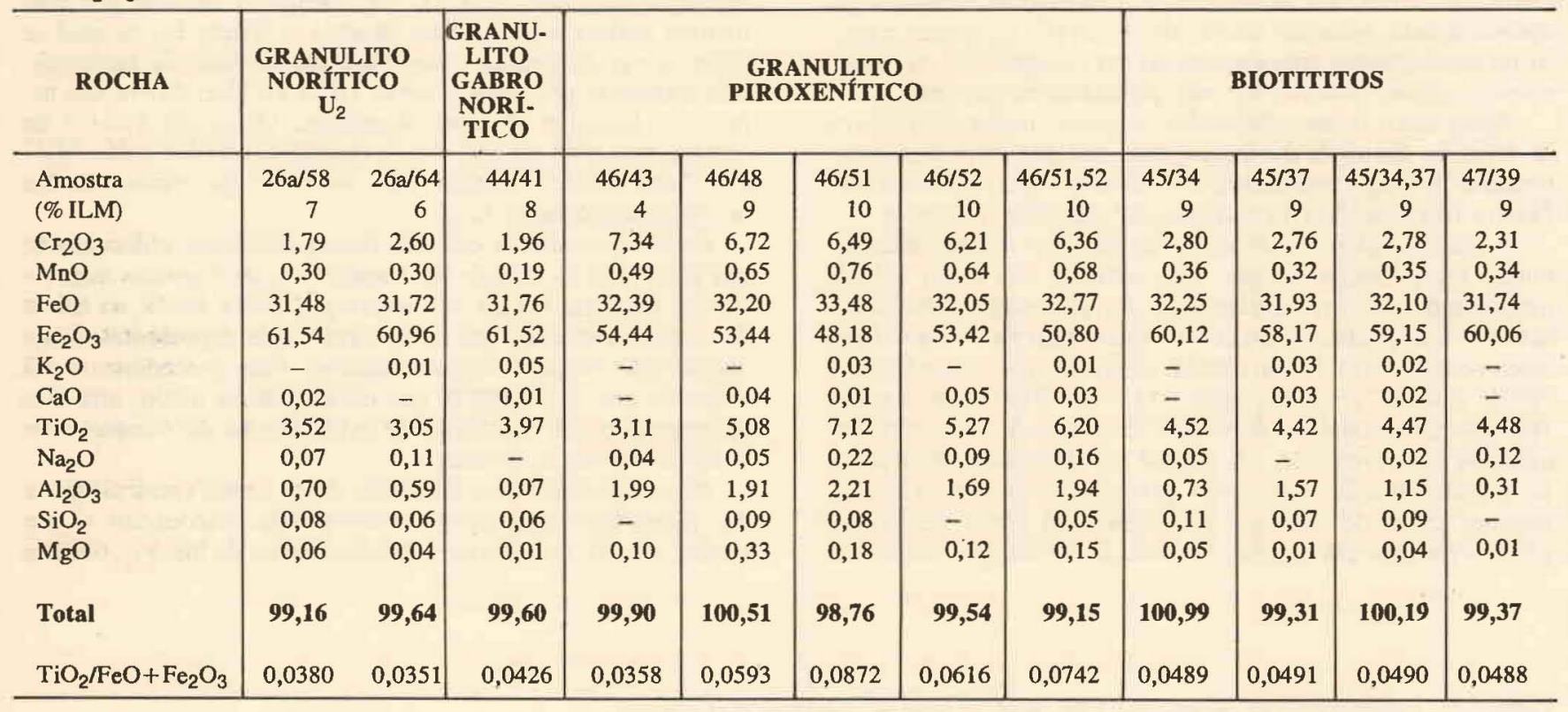

Tabela 7 - Composição original de ilmenitas (recalculadas com base nas ilmenitas mais ricas em $\mathrm{Fe}_{2} \mathrm{O}_{3}$ )

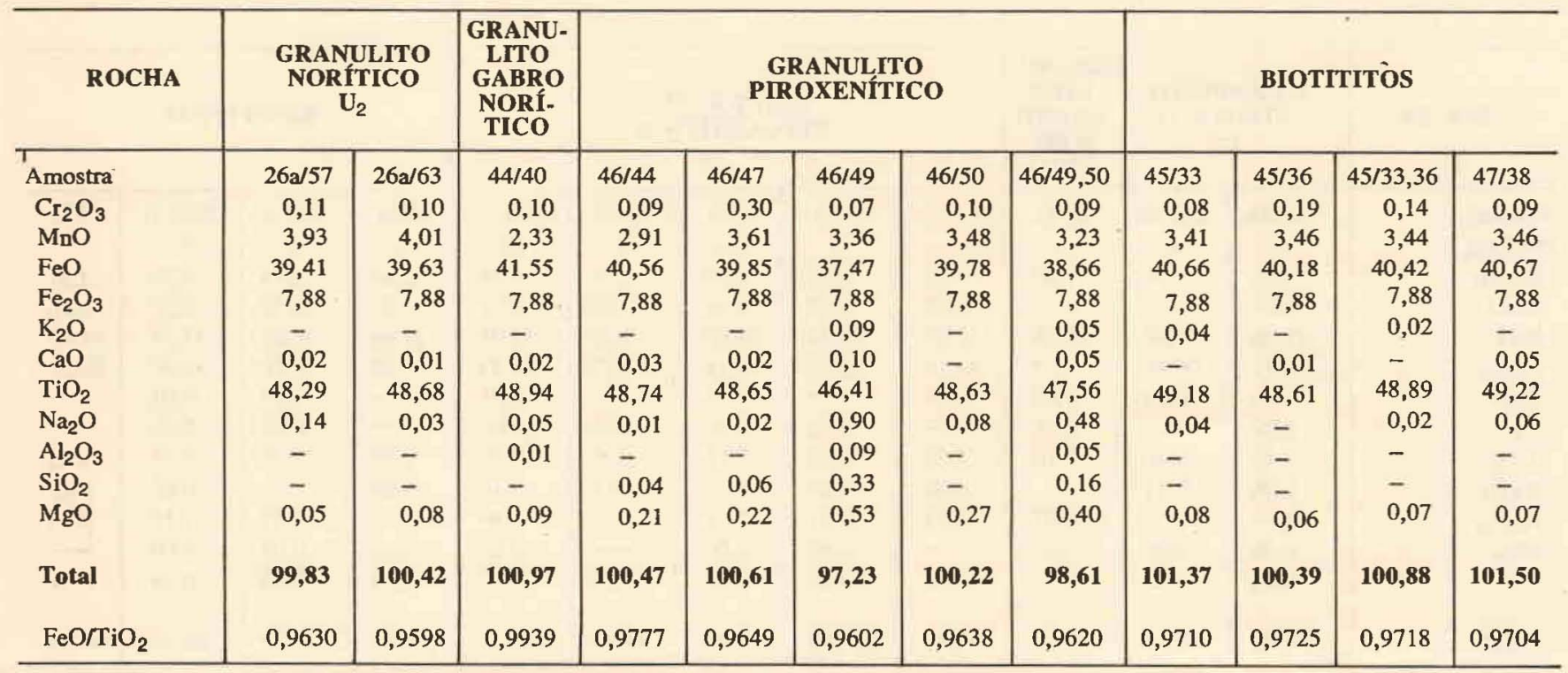


Tabela 8 - Geotermometria/barometria de oxigênio: (óxidos de Fe e Ti com reintegração de ilmenitas secundárias recalculadas em magnetitas e estimativa da composiçäo original da ilmenita

\begin{tabular}{|c|c|c|c|c|c|c|c|c|}
\hline (MT) & Amostra & (ILM) & $\mathrm{X}_{\text {USP }}$ & $\frac{{ }_{M T}^{X}}{\text { tita) }}$ & $X_{\text {HEM }}$ & $\begin{array}{c}\mathbf{X} \\
\text { IILM } \\
(\text { Ilmenita })_{\text {SS }}\end{array}$ & $\mathrm{T}\left({ }^{\circ} \mathrm{C}\right)$ & $\log f \mathrm{O}_{2}$ \\
\hline $26 \mathrm{a} / 58$ & - & $26 a / 57$ & 10,60 & 89,40 & 8,66 & 91,34 & 625 & $-17,49$ \\
\hline $26 \mathrm{a} / 64$ & - & $26 a / 63$ & 9,90 & 90,10 & 8,63 & 91,37 & 617 & $-17,68$ \\
\hline $44 / 41$ & - & $44 / 40$ & 11,92 & 88,08 & 8,24 & 91,76 & 633 & $-17,44$ \\
\hline $46 / 43$ & - & $46 / 44$ & 10,31 & 89,69 & 8,43 & 91,57 & 619 & $-17,69$ \\
\hline $46 / 45$ & - & $46 / 46$ & 21,40 & 78,60 & 13,56 & 86,44 & 780 & $-13,37$ \\
\hline $46 / 48$ & - & $46 / 47$ & 16,90 & 83,10 & 8,55 & 91,45 & 681 & $-16,32$ \\
\hline $46 / 51$ & - & $46 / 49$ & 24,35 & 75,65 & 9,05 & 90,95 & 742 & $-14,95$ \\
\hline $46 / 52$ & - & $46 / 50$ & 17,43 & 82,57 & 8,58 & 91,42 & 685 & $-16,22$ \\
\hline $46 / 51,52$ & - & $46 / 49,50$ & 20,85 & 79,15 & 8,80 & 91,20 & 714 & $-15,57$ \\
\hline $45 / 34$ & - & $45 / 33$ & 13,76 & 86,24 & 8,40 & 91,60 & 652 & $-16,97$ \\
\hline $45 / 37$ & - & $45 / 36$ & 13,72 & 86,28 & 8,51 & 91,49 & 653 & $-16,91$ \\
\hline $45 / 34,37$ & - & $45 / 33,36$ & 13,72 & 86,28 & 8,46 & 91,54 & 653 & $-16,94$ \\
\hline $45 / 39$ & - & $45 / 38$ & 13,48 & 86,52 & 8,42 & 91,58 & 650 & $-17,01$ \\
\hline
\end{tabular}

a partir dessa aproximação, situam-se, respectivamente, entre $780^{\circ} \mathrm{C}$ e $675^{\circ} \mathrm{C}$ e $-13,37$ e $-15,24$ (Tab. 11 e Fig. 1d), tendo havido um decréscimo ainda maior no intervalo original. Os pontos no diagrama da figura 1d encontram-se mais afastados da curva-tampão QFM, em direçāo a HM, apresentando, geralmente, poucas dispersōes.

Deve ser enfatizado que os métodos de reintegração utilizados são muito discutíveis, devido, principalmente, às imprecisōes nas determinaçōes volumétricas, que sāo extrapoladas a partir de contagens realizadas no plano, podendo ser ou super, ou subestimadas. Além disso, existem dificuldades em se definir quando as ilmenitas constituem realmente fases primárias, havendo maior segurança apenas no caso de cristais isolados, não associados à magnetita. Quando esses minerais ocorrem juntos, nem sempre é possível concluir, a partir das observaçōes texturais, se eles estão em equilíbrio, se a ilmenita constitui um intercrescimento em grânulo externo na magnetita, ou ainda se existem associaçōes entre esses dois modos de ocorrência.

$\mathrm{O}$ alto conteúdo em $\mathrm{TiO}_{2}$ das ilmenitas de Surubim sugere, em muitos casos, uma origem primária, isto é, não proveniente da exsolução por oxidação das magnetitas. Esse excesso de $\mathrm{TiO}_{2}$, no entanto, também pode ser explicado como sendo devido a reequilibrios dessa fase com magnetita titanífera ou a reaçōes entre os óxidos e parte dos silicatos, líquido ou fase fluida, durante o resfriamento, não podendo ser descartada a hipótese da ocorrência de uma reintegração entre ilmenitas primárias e secundárias.

Os intervalos relativamente amplos de temperatura e log $f \mathrm{O}_{2}$, bem como as dispersōes observadas em alguns diagramas, podem resultar dessas imprecisōes, embora o método permita uma boa aproximação para as condiçōes de metamorfismo.

CONCLUSÕES A correta interpretação das texturas apresentadas pelos óxidos de ferro e titânio, numa associaçāo em equilíbrio, pode servir de base para cálculos de geotermometria e barometria de oxigênio.

Tratando-se de rochas que sofreram mais de um evento metamórfico, ou retrometamorfismo, é possivel determinar as temperaturas máximas do pico do metamorfismo, bem como os valores de $\mathrm{fO}_{2}$ prevalecentes durante o mesmo; também podem ser obtidas indicaçōes sobre a história térmica do resfriamento ou de reaquecimentos em condiçōes menos drásticas.

Para a determinação das condições do pico do metamorfismo, são necessários cálculos que permitam a estimativa das composiçōes originais das ilmenitas, uma vez que as mesmas se modificam com o resfriamento. Esses cálculos apenas podem ser realizados de modo aproximado, considerando-se que

Tabela 9 - Composição de magnetitas com reintegração de ilmenitas secundárias recalculadas (com base na razão $\mathrm{FeO}^{*} / \mathrm{Ti} \mathrm{O}_{2}$ das ilmenitas mais ricas em $\mathrm{Fe}_{2} \mathrm{O}_{3}$

\begin{tabular}{l|c|c|c|c|c|c|c|r|r|r}
\hline Amostra & $26 \mathrm{a} / 58$ & $26 a / 64$ & $44 / 41$ & $46 / 43$ & $46 / 48$ & $46 / 52$ & $45 / 34$ & $45 / 37$ & $45 / 39$ & $45 / 34,37$ \\
\hline $\mathrm{Cr}_{2} \mathrm{O}_{3}$ & 1,79 & 2,60 & 1,96 & 7,35 & 6,72 & 6,23 & 2,80 & 2,75 & 2,31 & 2,78 \\
$\mathrm{MnO}$ & 0,29 & 0,29 & 0,19 & 0,53 & 0,68 & 0,68 & 0,37 & 0,33 & 0,35 & 0,36 \\
$\mathrm{FeO}$ & 31,28 & 31,54 & 31,56 & 32,23 & 31,90 & 31,73 & 31,95 & 31,67 & 31,44 & 31,82 \\
$\mathrm{Fe}_{2} \mathrm{O}_{3}$ & 61,54 & 61,31 & 61,87 & 54,67 & 53,98 & 54,02 & 60,61 & 58,66 & 60,55 & 59,64 \\
$\mathrm{~K}_{2} \mathrm{O}$ & - & 0,01 & 0,05 & - & - & - & - & 0,03 & - \\
$\mathrm{CaO}$ & 0,02 & - & 0,01 & - & 0,04 & 0,05 & - & 0,03 & - \\
$\mathrm{TiO}_{2}$ & 3,31 & 3,05 & 3,76 & 2,98 & 4,79 & 4,95 & 4,21 & 4,17 & 4,17 \\
$\mathrm{Na}_{2} \mathrm{O}$ & 0,07 & 0,11 & - & 0,04 & 0,05 & 0,08 & 0,04 & - & 0,12 & 0,02 \\
$\mathrm{Al}_{2} \mathrm{O}_{3}$ & 0,70 & 0,59 & 0,07 & 1,99 & 1,91 & 1,69 & 0,73 & 1,57 & 0,35 \\
$\mathrm{SiO}_{2}$ & 0,08 & 0,06 & 0,06 & - & 0,09 & 0,01 & 0,11 & 0,07 & - \\
$\mathrm{MgO}$ & 0,07 & 0,04 & 0,01 & 0,10 & 0,33 & 0,11 & 0,05 & 0,02 & 0,01 & 0,09 \\
Total & 99,15 & 99,60 & 99,54 & 99,89 & $\mathbf{1 0 0 , 4 9}$ & $\mathbf{9 9 , 5 5}$ & $\mathbf{1 0 0 , 8 7}$ & $\mathbf{9 9 , 3 0}$ & $\mathbf{9 9 , 3 0}$ & $\mathbf{1 0 0 , 1 2}$ \\
\hline
\end{tabular}


Tabela 10 - Composiçāo original de ilmetitas (recalculadas com base na razão $\mathrm{FeO} / T \mathrm{TiO}_{2}$ das ilmenitas mais ricas em $\mathrm{Fe}_{2} \mathrm{O}_{3}$ )

\begin{tabular}{|c|c|c|c|c|c|c|c|c|c|c|c|c|c|c|c|}
\hline Amostra & $36 / 55$ & $26 a / 57$ & $26 a / 61$ & $26 \mathrm{a} / 63$ & $44 / 40$ & $44 / 42$ & $46 / 44$ & $46 / 47$ & $46 / 50$ & $45 / 33$ & $45 / 36$ & $45 / 38$ & $45 / 33,36$ & $47 / 66$ & $47 / 70$ \\
\hline $\mathrm{Cr}_{2} \mathrm{O}_{3}$ & 0,08 & 0,12 & 0,11 & 0,11 & 0,10 & 0,06 & 0,10 & 0,32 & 0,11 & 0,08 & 0,21 & 0,10 & 0,15 & 0,09 & 0,12 \\
\hline $\mathrm{MnO}$ & 2,42 & 4,20 & 3,85 & 4,21 & 2,41 & 2,03 & 3,12 & 3,90 & 3,72 & 3,59 & 3,74 & 3,67 & 3,67 & 2,13 & 2,38 \\
\hline $\mathrm{FeO}$ & 38,97 & 36,42 & 36,63 & 36,46 & 39,01 & 39,69 & 37,69 & 36,56 & 36,70 & 37,37 & 37,13 & 37,23 & 37,23 & 35,66 & 39,27 \\
\hline $\mathrm{Fe}_{2} \mathrm{O}_{3}$ & 12,34 & 14,07 & 13,60 & 14,05 & 12,22 & 11,77 & 13,20 & 13,87 & 13,90 & 13,38 & 13,51 & 13,48 & 13,48 & 13,73 & 12,01 \\
\hline $\mathrm{K}_{2} \mathrm{O}$ & & & & & & & & & & 0,04 & & 0,02 & $.0,02$ & & 0,03 \\
\hline $\mathrm{CaO}$ & 0,07 & 0,02 & & 0,01 & 0,02 & & 0,03 & 0,02 & & & 0,01 & & & 0,04 & \\
\hline $\mathrm{TiO}_{2}$ & 46,29 & 45,37 & 45,26 & 45,46 & 46,33 & 46,55 & 45,91 & 45,40 & 45,58 & 45,76 & 45,66 & 45,70 & 45,70 & 44,48 & 46,36 \\
\hline $\mathrm{Na}_{2} \mathrm{O}$ & & 0,15 & & 0,03 & 0,05 & 0,02 & 0,01 & 0,02 & 0,09 & 0,04 & & 0,02 & 0,02 & 0,03 & 0,02 \\
\hline $\mathrm{Al}_{2} \mathrm{O}_{3}$ & & & & & 0,01 & & & & & & & & & 1,52 & \\
\hline $\mathrm{SiO}_{2}$ & & & & & & & 0,04 & 0,06 & & & & & & 1,47 & 0,01 \\
\hline $\mathrm{MgO}$ & 0,06 & 0,06 & 0,09 & 0,08 & 0,09 & 0,06 & 0,22 & 0,24 & 0,29 & 0,08 & 0,07 & 0,08 & 0,08 & 1,19 & \\
\hline Total & 100,23 & 100,40 & 99,54 & 100,41 & 100,24 & 100,18 & 100,32 & 100,39 & 100,39 & 100,34 & 100,33 & 100,36 & 100,35 & 100,34 & 100,20 \\
\hline
\end{tabular}

as ilmenitas mais ricas em $\mathrm{Fe}_{2} \mathrm{O}_{3}$ sejam as que sofreram menores modificações com o resfriamento. Também deve ser realizada a reintegração das ilmenitas secundárias nas magnetitas hospedeiras para obtenção da composição da solução sólida original, o que é feito pelas proporçōes modais dessas fases, expressas como porcentagens em peso.

As indicaçōes da história do resfriamento subsólido, por sua vez, são obtidas pela aplicaçāo dos métodos geotermobarométricos, considerando-se as composiçōes de magnetita e ilmenita atualmente presentes.

As relaçōes texturais observadas entre os 6xidos de ferro e titânio de Surubim registram a complexidade da história metamórfica e dos fenômenos de resfriamento subsólido, a partir do pico do metamorfismo granulítico.

Pelo estudo das seçōes delgadas e polidas, observou-se, nas rochas mais preservadas da regiāo, texturas granoblásticas de equilíbrio, que apresentam, entre outras, a associação magnetita + ortopiroxênio \pm ilmenita \pm espinélio (hercinita), nāo tendo sido identificado nenhum tipo de textura ígnea reliquiar. Somente estāo bem preservadas feiçōes que denotam o metamorfismo granulítico e os fenômenos retrometamórficos posteriores; assim, apenas com base em observaçōes texturais, pouco pode ser deduzido a respeito dos eventos anteriores ao metamorfismo.

Considerando-se, entāo, a cristalizaçāo ou recristalização de magnetita e ilmenita em equilíbrio no fácies granulito, tentou-se estabelecer as condiçōes metamórficas pela formulaçāo termodinâmica de Powell \& Powell (1977) para o método de Buddington \& Lindsley (1964).

Aplicando-se o método a partir das composiçôes atuais dessas fases, obteve-se uma variação bastante ampla de T e $\mathrm{fO}_{2}$, estando os menores valores de temperatura fora do intervalo de calibraçāo de Buddington \& Lindsley (1964). As feiçōes mineralógicas e texturais das amostras estudadas sugerem intensos reequilíbrios entre ilmenita, magnetita, silicatos, líquidos ou fases fluidas no decorrer do resfriamento subsólido. Por isso não é possível a dedução mais precisa sobre as etapas de resfriamento, embora os resultados sugiram que este se tenha dado continuamente, aproximando-se da curva-tampão HM, e os reequilíbrios subsólidos tenham cessado a temperaturas bastante baixas.

Com os métodos de reintegração, foram obtidos intervalos de $\mathrm{T}$ e $\log f \mathrm{O}_{2}$ bem mais restritos $\left(\mathrm{T}=617^{\circ} \mathrm{C}-780^{\circ} \mathrm{C} / \mathrm{log}\right.$ $f \mathrm{O}_{2}=-17,68$ a $-13,37$ ou $\mathrm{T}=675^{\circ} \mathrm{C}-780^{\circ} \mathrm{C} / \log f_{\mathrm{O}_{2}}=$ $-15,24$ a $-13,37)$, com melhor definição das condiçôes metamórficas.

Os óxidos de ferro e titânio de Surubim, Vale do Curaçá, Bahia, permitem, portanto, a determinaçāo, com boa aproximação, das condiçōes do pico do metamorfismo granulítico, com valores médios de temperatura semelhantes aos obtidos por outros geotermômetros relativos a minerais silicáticos coexistentes (Bello 1986, Bello et al. 1986), além de fornecerem indicaçōes sobre a história do resfriamento subsólido da regiāo.

Agradecimentos Os autores agradecem as críticas e sugestōes do Professor Dr. João Batista Moreschi; à Sra. Marta J. Silva, pela datilografia dos originais; e ao $\mathrm{CNPq}$, pelo suporte financeiro concedido por intermédio de Bolsa de Pesquisa Recém-Doutor a um dos autores (Proc. 303872/85-GL, beneficiária Rosa Maria da Silveira Bello).

Tabela 11 - Geotermometria/barometria: de oxigênio (b́xidos de Fe e Ti, com reintegraçāo de ilmenitas secundárias recalculadas em magnetita e estimativa da composição original das ilmenitas, com base na razão $\mathrm{FeO} * / T i \mathrm{O}_{2}$ das ilmenitas mais ricas em $\mathrm{Fe}_{2} \mathrm{O}_{3}$

\begin{tabular}{|c|c|c|c|c|c|c|c|c|}
\hline (MT) & $\begin{array}{l}\text { Amostra } \\
-(\mathrm{MT}) /(\mathrm{ILM})\end{array}$ & $\begin{array}{l}\text { (\% ILM) } \\
\text { Secundária }\end{array}$ & $\mathbf{X}_{\text {USP }}$ & $\underset{\text { MT }}{\text { X }_{(\text {Magnetita }} \text { SS }_{\text {SS }}}$ & $\mathrm{X}_{\text {HEM }}$ & $\begin{array}{c}\mathbf{X}_{\text {ILM }} \\
(\text { IImenita) } \\
\text { SS }\end{array}$ & $\mathbf{T}\left({ }^{\circ} \mathbf{C}\right)$ & $\log f \mathrm{O}_{2}$ \\
\hline $26 a$ & - $58 / 57$ & $61(7)$ & 9,96 & 90,04 & 15,46 & 84,54 & 687 & $-14,79$ \\
\hline $26 a$ & - $64 / 63$ & $61(6)$ & 9,20 & 90,80 & 15,43 & 84,57 & 677 & $-15,00$ \\
\hline 44 & $-41 / 40$ & $40(8)$ & 11,20 & 88,80 & 12,91 & 87,09 & 679 & $-15,40$ \\
\hline 46 & $-\quad 43 / 44$ & (47) 4 & 9,86 & 90,14 & 14,22 & 85,78 & 675 & $-15,24$ \\
\hline 46 & $-45 / 46$ & 0 & 21,40 & 78,60 & 13,56 & 86,44 & 780 & $-13,37$ \\
\hline 46 & - $48 / 47$ & $(47) 9$ & 15,85 & 84,15 & 15,23 & 84,77 & 749 & $-13,66$ \\
\hline 46 & $-52 / 50$ & (47) 10 & 16,37 & 83,63 & 15,21 & 84,79 & 754 & $-13,58$ \\
\hline 45 & $-34 / 33$ & $33(9)$ & 12,75 & 87,25 & 14,50 & 85,50 & 711 & $-14,49$ \\
\hline 45 & - $37 / 36$ & (33) 9 & 13,02 & 86,98 & 14,70 & 85,30 & 716 & $-14,37$ \\
\hline 45 & $-\quad 39 / 38$ & (33) 9 & 12,60 & 87,40 & 14,72 & 85,28 & 711 & $-14,45$ \\
\hline 45 & - $34,37 / 33,36$ & (33) 9 & 12,87 & 87,13 & 14,63 & 85,37 & 714 & $-14,42$ \\
\hline
\end{tabular}




\section{REFERÊNCIAS BIBLIOGRÁFICAS}

ANDERSON, A.T. 1968. Oxidation of the LaBlache Lake titaniferous magnetite deposit, Quebec. J. Geol., 76:528-547.

BELLO, R.M.S, 1986. Jazida de cobre de Surubim, Vale do Curaç, BA: mineralogia, petrografia e petrogênese. Säo Paulo, 426 p. (Tese de Doutoramento, IG-USP).

BELLO, R.M.S.; SCHULTZ, R.A.; VALARELLI, J.V. 1986 Influência do $\mathrm{Al}_{2} \mathrm{O}_{3}$ no geotermómetro opx-cpx de amostras de Surubim, Bahia. An. Acad. bras. Ciênc., 58(1):164.

BELLO, R.M.S. \& VALARELLI, J.V. 1986. Ocorrência de teluretos no minério de cobre de Surubim, Vale do Curaçá, Bahia. An. Acad. bras. Ciênc., 58(1):164.

BOHLEN, S.R. \& ESSENE, E.J. 1977. Feldspar and oxide thermometry of granulites in the Adirondack Highlands. Contrib. Mineral. Petrol., 62:153-169.

BOHLEN, S.R.; ESSENE, E.J.; HOFFMAN, K.S. 1980. Update on feldspar and oxide thermometry in the Adirondack Mountains, New York. Geol. Soc. Am. Bull., 91(1):110-113.

BUDDINGTON, A.F. \& LINDSLEY, D.H. 1964. Iron-titanium oxide minerals and synthetic equivalents. J. Petrol., 5(2):310-357.

SILVA, L.J.H.D.R. 1985. Geologia e controle estrutural do depósito cuprffero de Caraba, Vale do Curaça, Bahia. SME/CPM, p. 51-121. (Śrie Textos Básicos, v. 6

EUGSTER, H.P. \& WONES, D.R. 1962. Stability relations of the ferruginous biotite, annite. J. Petrol., 3(1):82-125.

FIGUEIREDO, M.C.H. 1976. Geologia e geoqufmica da regiāo de Poço de Fora-Vale do Rio Curuçá, Bahia. Salvador, 87p. (Dissertaçāo de Mestrado, UFBA)

FIGUEIREDO, M.C.H. 1981. Geaquínica das rochas metamorficas de alto grau do nordeste da Bahia, Brasil. Bahia, SME/CPM, p. 1-71. (Série Textos Básicos 4)

FRANKE, N.D.; REINHARDT, M.C. BELLO, R.M.S; CARVALHO, P.R.S.; MORAES, J.A. 1982. Geologia do depósito cuprifero de Surubim, Bahia. 30p. (Caraíba Metais S/A. Relatório. Inédito)

HAGGERTY, S.E. 1967a. Oxidation of opaque mineral oxides in basalts. In: RUMBLE III, D. ed. Oxide minerals. Min. Soc. Amer. Short Course Notes, p. $\mathrm{Hg} 1-100$.

HAGGERTY, S.E. 1976b. Opaque mineral oxides in terrestrial igneous rocks. In: RUMBLE III, D. ed. Oxide minerals. Min. Soc. Amer. Short Course Notes, p. Hg 101-300.

HAMMOND, P.A. \& TAYLOR, L.A. 1982. A ilmenite-titanomagnetite assemblage: kinetics of reequilibration. Earth Planet. Sci.Let., 61(1):143-150.

HARLEY, S.L. \& GREEN, D.H. 1982. Garnet - orthopyroscere barometry for granulites and peridotetes. Nature, 300:697-701

HÂSUI, Y.; SILVA, L.J.H.D.R.; LIMA e SILVA, F.J.; MANDETTA, P.; MORAES, J.A.C.; OLIVEIRA, J.G.; MIOLA, W. 1982. Geology and copper mineralizations of Curaçá River Valley, Bahia.Rev. Bras. Geoc., 12(1-3):463-474.
HASUI, Y.; D'EL REY SILVA; L.J.H.; LIMA E SILVA, F.J.; MANDETTA, P.; MORAES, J.A.C.; OLLIVEIRA, J.G.; MIOLA, W. 1982. Geology and copper mineralizations of Curuçá River Valley, Bahia. Rev. Bras. Geoc., 12(1-3):463-474.

JARDIM DE SA, E.F.; ARCHANJO, C.J.; LEGRAND, J.M. 1982. Structural and metamorphic history of part of the high-grade terrain in the Curuçá Valley, Bahia, Brazil. Rev. Bras. Geoc., 12(1-3):251-262.

LINDENMA YER, Z.G. 1981. Evoluçāo geologica do Vale do Curuçăe dos corpos máficos-ultramáficos mineralizados a cobre. Bahia, SME/CPM, p. 72-110. (Série Textos Básicos 4).

MAURY, R.C. \& D'ARCO, P. 1984. Applications des methods géotermobarométriques aux paragénèses minérales des roches volcaniques. In: LAGACHE, M. ed. Thermométrie et barométrie géologiques. Societé Française de Minéralogie et de Cristallographic. Jussieu, Paris, p. 283-310.

POWELL, R. \& POWELL, M. 1977. Geothermometry and oxygen barometry using coexisting iron-titanium oxides: a reapraisal. Mineral. Mag., 41:257-263.

RAMDOHR, P. 1953. Ulvöspinel and its significance in titaniferous iron ores. Econ. Geol., 48:677-688.

REYNOLDS, I.M. 1980. Ore petrography and mineralogy of the vanadium-bearing titaniferous magnetite layer of the Kaffirskraal intrusion, Heidelberg District, Transvaal. Trans. Geol. Soc. S. Afr., 83:221-230.

REYNOLDS, I.M. 1981. The mineralogy and petrography of some titaniferous iron ores from the Usushwana Complex. Trans. Geol. Soc. S. Afr., 84:261-269.

REYNOLDS, I.M. 1983. The iron-titanium oxide mineralogy of Karoo dolerite in the Eastern Cape and Southern Orange Free State. Trans. Geol. Soc. S. Afr., 86:211-220.

ROLLINSON, H.R. 1980. Iron-titanium oxides as an indicator of the role of the fluid phase during the cooling of granites metamorphosed to granulite grade. Mineral. Mag., 43:623-631.

SÁ, E.P. de \& REINHARDT, M.C. 1984. Aspectos metodologicos da prospecçāo mineral no Vale do Rio Curucá, Bahia. In: SIMPÓSIO BRASILEIRO SOBRE TÉCNICAS EXPLORATÓRIAS APLICADAS À GEOLOGIA, Salvador, 1984. Anais... Salvador, SBG, p. 250-278.

THY, P. 1982. Titanomagnetite and ilmenite in the Fongen-Hyllingen basic complex, Norway. Lithos., 15:1-16.

MANUSCRTTO 513

Recebido em 17 de dezembro de 1987 Revisāo aceita em 21 de março de 1988 